\title{
Review Article \\ Efficient Hepatic Delivery of Drugs: Novel Strategies and Their Significance
}

\author{
Nidhi Mishra, ${ }^{1}$ Narayan Prasad Yadav, ${ }^{1}$ Vineet Kumar Rai, ${ }^{1}$ Priyam Sinha, \\ Kuldeep Singh Yadav, ${ }^{1}$ Sanyog Jain, ${ }^{2}$ and Sumit Arora ${ }^{2}$ \\ ${ }^{1}$ Herbal Medicinal Products Department, CSIR-Central Institute of Medicinal and Aromatic Plants (CSIR-CIMAP), \\ Lucknow 226015, India \\ ${ }^{2}$ Centre of Pharmaceutical Nanotechnology, Department of Pharmaceutics, National Institute of Pharmaceutical Education \\ and Research (NIPER), Sector 67, SAS Nagar, Mohali, Punjab 160062, India
}

Correspondence should be addressed to Narayan Prasad Yadav; npyadav@gmail.com

Received 24 April 2013; Revised 14 August 2013; Accepted 25 August 2013

Academic Editor: Umesh Gupta

Copyright (C) 2013 Nidhi Mishra et al. This is an open access article distributed under the Creative Commons Attribution License, which permits unrestricted use, distribution, and reproduction in any medium, provided the original work is properly cited.

\begin{abstract}
Liver is a vital organ responsible for plethora of functions including detoxification, protein synthesis, and the production of biochemicals necessary for the sustenance of life. Therefore, patients with chronic liver diseases such as viral hepatitis, liver cirrhosis, and hepatocellular carcinoma need immediate attention to sustain life and as a result are often exposed to the prolonged treatment with drugs/herbal medications. Lack of site-specific delivery of these medications to the hepatocytes/nonparenchymal cells and adverse effects associated with their off-target interactions limit their continuous use. This calls for the development and fabrication of targeted delivery systems which can deliver the drug payload at the desired site of action for defined period of time. The primary aim of drug targeting is to manipulate the whole body distribution of drugs, that is, to prevent distribution to non-target cells and concomitantly increase the drug concentration at the targeted site. Carrier molecules are designed for their selective cellular uptake, taking advantage of specific receptors or binding sites present on the surface membrane of the target cell. In this review, various aspects of liver targeting of drug molecules and herbal medications have been discussed which elucidate the importance of delivering the drugs/herbal medications at their desired site of action.
\end{abstract}

\section{Introduction}

In the last decade, significant advances have been made in the development of plant-based hepatoprotective drugs mostly because of their lower toxicity and a multi-factorial approach to restoring health, seeking equilibrium between mind, body, and environment and placing a greater emphasis on the multidimensional elements of health than on pathology alone. Along with drugs, phytomedications have increasingly been prescribed for the treatment of a number of diseases. However, phytotherapeutics needs a scientific approach to deliver the components in a sustained manner so as to increase patient compliance and avoid repeated administration. This can be achieved by designing novel drug delivery systems (NDDS) for herbal constituents, in addition to the drugs already available in the market. Novel drug delivery systems not only reduce the repeated administration (due to its sustained-release properties) to overcome noncompliance but also help to increase the therapeutic value by reducing toxicity, increasing the bioavailability, stability, and targetability to a specific cell or organ (due to its subcellular size). For a long time, herbal medicines were not considered for development as novel formulations owing to the lack of scientific justification and processing difficulties, such as standardization, extraction, and identification of individual drug components in complex polyherbal systems. However, modern phytopharmaceutical research solves the scientific needs for herbal medicines as in modern medicine, which gives way for developing novel formulations such as nanoparticles, microemulsions, matrix systems, solid dispersions, liposomes, and solid lipid nanoparticles.

However, for delivery to specific cell type of liver, novel drugs delivery system for herbal drugs, still needs some modification such as attaching of ligand or targeting moiety 
which will recognize and interact with specific cell type of liver. In the present review, we enumerate all the methods for attaching targeting moiety to delivery system and different factors which could be taken into account while designing NDDS for liver cell which will be of immense importance in near future. The review elucidates the importance of delivery of both the drugs and herbal medications to the liver so as to ensure successful treatment outcomes.

\section{Morphological Study of Liver}

Before discussing the different methods of targeting, it is necessary to understand the morphology of liver (especially vascular supply) and molecular scale of the target tissue in order to design a novel drug delivery system rationally.

The liver engages numerous metabolic, immunological, and endocrine functions. It receives blood (oxygenated and deoxygenated) from the gut and heart via the portal vein and hepatic artery, respectively. Blood circulates through a permeable discontinuous capillary network term as the sinusoids to reach the central and hepatic veins. The sinusoids are small blood vessels (5 to $10 \mu \mathrm{m}$ wide) between the radiating rows of hepatocytes having fenestrations of size $100-150 \mathrm{~nm}$ (depending on the type of animal species). They allow almost unrestricted passage of plasma components to the perisinusoidal space, where the cords of parenchymal cells called as hepatocytes are situated. Inside the sinusoid capillaries, the Kupffer cells are responsible for phagocytic activity of the liver $[1,2]$.

2.1. Phagocytosis in Kupffer Cells. Phagocytosis occurs after the multivalent drug delivery system comes in contact with the macrophage where they spread the cell membrane around the particles to engulf them. Macrophages recognize the delivery systems via the recognition of opsonins present over them or through interaction with scavenger receptors present on Kupffer cells. After ingestion, phagocytic vesicle (phagosomes) coalesces with intracellular organelles containing digestive proteins having acidic internal $\mathrm{pH}$, to mature into phagolysosomes and to degrade the internal part of the delivery system. The delivery system is then eliminated by exocytosis after degradation or is sequestered in residual bodies within the cell if it cannot be digested [3, 4].

2.2. Macrophages Interaction with the Delivery System. The following factors should be taken into account while discussing the interaction of macrophages with the delivery system.

Size and Radius. The interaction between the macrophages and delivery system could be influenced by the size and radius of curvature of delivery system. Generally, a diameter of $1-3 \mu \mathrm{m}$ (in vitro limit is $20 \mu \mathrm{m}$ ) is sufficient for interaction as Kupffer cell has ruffled surface. Too small particles co-operate less with the cell membrane and gain entry into the cell through the other side like pinocytosis or endocytosis while the larger particle fails to contact with the cell membrane.

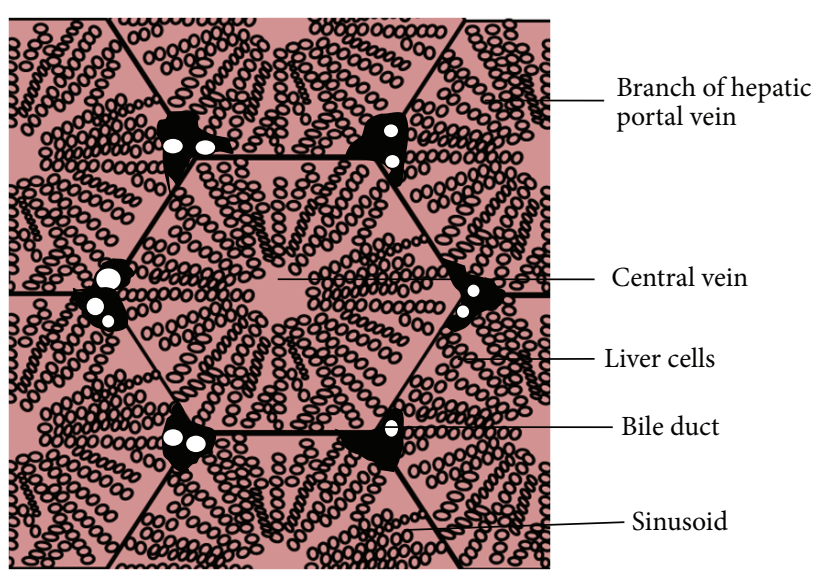

FIgURE 1: Microscopic view of liver cells.

Shape. The shape has great impact on the interaction of delivery system and macrophages. For larger particles, elongated shapes promote interaction while for smaller particle shape influences the speed of internalization and the different pathways used to enter the cells. Some studies have shown that, in comparison to their spherical shape, nonspherical particles are steered into distinctive tissue distribution patterns by hydrodynamic forces in the bloodstream, for example, filomicelles with very high aspect ratios $(>10)$ and longitudinal lengths around $10 \mu \mathrm{m}$ achieve considerably longer circulation times than spherical particles.

Flexibility and Deformability. These are other parameters that also influence the interaction and distribution. The flexibility of smaller hydrophilic delivery system (approximately $200 \mathrm{~nm}$ ) was found to affect in vitro kinetics and internalization pathways in macrophages [5] and other nonphagocytic cells [6]. In vivo, the flexibility and deformability of delivery systems have great impact on their tissue distribution and retention, for example, RBC.

Surface Properties. These properties influence interaction in a complex manner. Positive charges on the surface of delivery system have deleterious effect on circulation times, whereas contrary findings are reported regarding the impact of negative charge. For example, He et al. [7] studied the effects of particle size and surface charge on cellular uptake/biodistribution and concluded that in vivo biodistribution of nanoparticles (NPs) with slight negative charges and particle size of $150 \mathrm{~nm}$ tended to accumulate in tumor more efficiently, while Funato et al. and Nishikawa et al. [8,9] reported that negatively charged liposomes have a shorter half-life in the blood. Figure 1 provides a microscopic view of the liver surface.

\section{Essential Attributes for Designing Delivery Systems for Liver Targeting}

For a therapeutic moiety to exert its desired effect, it needs to be in physical contact with its physiological target such as a receptor present on liver cells. Site-specific drug delivery 
ensures that such interactions take place only in the desired anatomical location of the liver; therefore, it must fulfil the following criteria: (i) it must be able to cross the anatomical barriers such as those of stomach and intestine, (ii) should be recognized selectively by the receptor present on liver cell such as asialoglycoprotein, (iii) exogenously delivered ligand for targeting should compete with the endogenously produced ligand, (iv) fabricated delivery system must be nontoxic, biocompatible, biodegradable, and physico-chemically stable in the liver cells either in vivo or in vitro, (v) it should have uniform sinusoid capillary distribution, (vi) should have controllable and predictable rate of drug release so that only therapeutic amount of drug is released to the liver cells, (vii) drug release should not affect the drug distribution, (viii) it should show minimal drug leakage during its passage through stomach, intestine, and other parts of the body, (ix) carrier used for encapsulating the herbal drugs must be eliminated from the body without imparting any sign of toxicity and no carrier should induce modulation of diseased state, and (x) lastly, preparation of drug delivery system should be easy or reasonably simple, reproducible, and cost-effective.

3.1. Pharmacokinetic Considerations. Pharmacokinetics also plays an important role in developing novel delivery systems of herbal drugs for liver, since the introduction of this tool enables us to quantitatively predict the disposition of drugs after modification. Some pharmacokinetic conditions must be fulfilled, to achieve a successful performance by site-selective drug-carrier delivery systems which are as follows.

\subsubsection{Rate of Elimination of Drug-Carrier Conjugate. Drug-} carrier conjugate should not be removed too rapidly from the systemic circulation rather should be removed in a controlled manner. All the nonspecific interactions between drug-carrier conjugate and the environment of the systemic compartment need to be eliminated during designing and development of targeted delivery systems. The carrier should have the ability to restrict all unwanted interactions between the drug and the physiological environment until drug is released at the target site $[10,11]$.

3.1.2. Rate of Release of Free Drug at the Non-Target Site. The release of drug at the non-target site could nullify any benefits that might potentially come from delivering the drug to the target site. This is because the amount of drug reaching at the nonspecific sites may cause toxicity owing to its high concentration.

\subsubsection{Rate of Delivery of Drug-Carrier Conjugate to the Target} Site. If the drug-carrier conjugate reaches the target site too slowly, the supply of free drug might never be sufficient to generate the concentration required to elicit the desired therapeutic effect at the site of action. The total amount of drug delivered (i.e., the area under the curve in a drug concentration versus time plot for the target site) is irrelevant if, at any time, the free-drug concentration at the target site does not reach its pharmacologically effective level. Delivery of the drug-carrier conjugate to the target organ may not guarantee that an adequate amount of the free drug will be available at the actual target.

3.1.4. Rate of Release of Free Drug at the Target Site. The capacity of the drug delivery system selected for the release of free drug from the conjugate should be considered. It needs to be suitable for processing the entirety of the drug-carrier conjugate arriving at the target site, doing so at a rate that also ensures drug accumulation at target site.

3.1.5. Rate of Removal of Free Drug from the Target Site. Drugs that benefit most from target selective delivery are those that are retained at the site while acting on their target of action. Therefore, drugs should be specifically designed to be used with target selective delivery systems and drug delivery should not be used for rescuing poorly performing, existing drugs. Certain drug (e.g., DNA in gene therapy) needs to be delivered into the cytoplasm; therefore, it would be preferential for the release of the drug to take place within the cells. This could lead to the enhanced retention of the drug in close proximity to its target. Furthermore, an increased rate of elimination of free drug from the central compartment tends to increase the advantage brought about as a result of drug targeting but also increases the required rate of input (of the drug carrier) to maintain a therapeutic effect [12].

\subsubsection{Rate of Elimination of the Drug-Carrier Conjugate and} Free Drug from the Body. For optimal targeting, elimination of the complete drug-carrier system should be minimal. These systems are too large to be eliminated via the kidneys [13]. Consequently, the liver is mainly responsible for the removal of drug conjugates from the circulation. The rate of elimination of free drug from the systemic circulation should be rapid relative to its rate of transfer from the target site to the central compartment of the body. This way, the drug-delivery system will achieve a decrease in the drug-associated toxicity.

\section{Formulation Aspects of Liver Targeting of Drugs}

Normally most of the drugs achieve high hepatic concentration, still their targeting is necessary because liver is the major organ in the body equipped for uptake, detoxification, metabolic transformation, and excretion of xenobiotics into bile by means of carrier-mediated mechanism. As a consequence, most of the drugs are rapidly cleared from the blood and display high first pass clearances by the liver. However, it should be realized that the total hepatic uptake predominantly depends on hepatocytes, whereas Kupffer cells largely contribute to hepatic uptake of particulate material. Therefore, the drugs that enter the liver as such or in the form of covalent carrier conjugates will not necessarily reach the required cell type. Moreover, if drugs are accumulated in the liver, their residence time in the organ is influenced by the factors discussed under macrophages interaction with delivery system and pharmacokinetic consideration. Thus, the challenge is to obtain selective accumulation of drugs in one specific cell type and to sustain intracellular levels for longer 
TABLE 1: Receptors present on various hepatic cell and may be used for drug targeting [25].

\begin{tabular}{|c|c|c|c|}
\hline Hepatocytes & Kupffer cells & Endothelial cell & Hepatic stellate cells \\
\hline $\begin{array}{l}\text { Asialoglycoprotein } \\
\text { receptor (ASGP-R) }\end{array}$ & Mannose/N-acetyl glucose amine $\mathrm{R}$ & $\begin{array}{l}\text { Mannose/N-acetyl glucose } \\
\text { amine R }\end{array}$ & M6P/IGF II R \\
\hline HDL-R & Galactose particle $\mathrm{R}$ & Scavenger R (Class A1 and A11) & $\alpha_{2}$ macroglobulin $\mathrm{R}$ \\
\hline LDL-R & Galactose specific $\mathrm{R}$ & Fc R immune complexes & Ferritin R \\
\hline $\operatorname{Ig} \mathrm{A}-\mathrm{R}$ & $\begin{array}{l}\text { Fc R (immune complexes, opsonized } \\
\text { material) }\end{array}$ & $\begin{array}{l}\text { Matrix compound (hyaluronan } \\
\text { fibronectin, denatured collagen } \\
\text { PIIINP) }\end{array}$ & Uroplasminogen $\mathrm{R}$ \\
\hline Scavenger R (Class BI) & $\begin{array}{l}\text { Scavenger R (Class AI, BI, BII, MARCO } \\
\text { CD36 and macrosialin) }\end{array}$ & & Thrombin R \\
\hline Transferrin $\mathrm{R}$ & LDL R matrix compounds (fibronectin) & & $\begin{array}{l}\text { RBP R matrix compounds } \\
\text { (intregrin, collagen type VI, } \\
\text { fibronectin } \mathrm{CD}_{44} \text { ) }\end{array}$ \\
\hline Insulin R & $\begin{array}{l}\text { Complement R (C3b and C1q) LPS R } \alpha_{2} \\
\text { macroglobulin R }\end{array}$ & & \\
\hline
\end{tabular}

${ }^{*} \mathrm{R}$ : Receptor.

period. The target cells/receptors within the liver for treatment and possible entry mechanisms in these cells have been identified (Table 1). Hepatocytes are functional units responsible for most of the metabolic and secretory activities of the liver. Small size delivery system, that is, $150 \mathrm{~nm}$, avoid capture by Kupffer cells and can diffuse out of the sinusoids through the fenestrations and reach the hepatocytes plates. These cells can take up colloidal carrier system through pinocytosis and receptor-mediated endocytosis. Improved delivery (enhanced localization) to the parenchyma is achieved with small size delivery system, that is, $\leq 50 \mathrm{~nm}$, that can diffuse deeper in the space of disse $[2,14,15]$. Specific targeting of hepatocyte receptors can also be achieved. The most commonly exploited target is the asialoglycoprotein receptor (ASGP-R) that recognizes carbohydrates (mainly galactose and $\mathrm{N}$-acetylgalactosamine) with variable affinity [16]. Since ASGP-R positive vesicles transit to the lysosomes, the increasingly acidic and oxidative conditions in organelles after endocytosis must be taken into account when targeting this pathway. Similarly, the upper size threshold for the internalization of colloids via ASGP-R seems to be situated below $90 \mathrm{~nm}$ [17]. This limits the type of carrier system which can be delivered through this route. Another approach consists of decorating delivery system with hepatocytes targeting lipoproteins either before administration $[18,19]$ or in situ after injection $[20,21]$. Although effective targeting to hepatocytes can be achieved, the ubiquitous nature of lipoprotein receptors in different tissues can lead to nonspecific distribution and subsequent side effects [22]. Finally, because non-parenchymal liver cells also possess physiological and pathological functions, their targeting can sometimes be desirable. Scavenging receptors can serve to target Kupffer and endothelial cells [21, 23], while coupling with vitamin A on the surface of colloidal delivery system revealed an effective way of delivering active to stellate cells that play a fundamental role in liver fibrosis [24].

4.1. Different Aspects of Formulation Design for Targeting to Liver. There are various methods for coupling of ligand

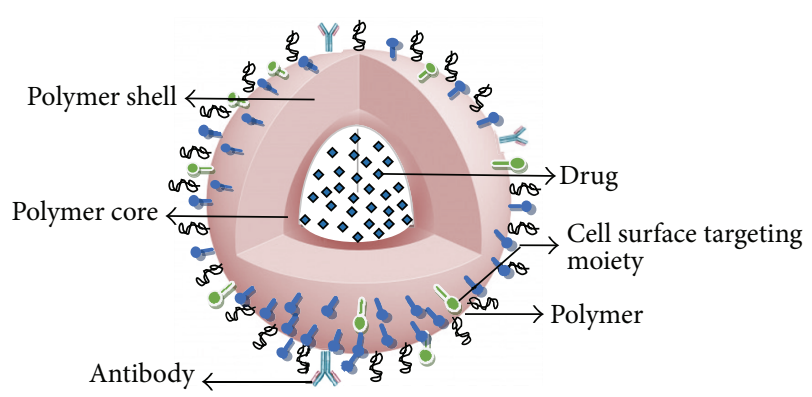

FIGURE 2: Drug delivery system encapsulating drug grafted with targeting moiety.

molecule on drug delivery system so that drug-carrier system can be targeted to liver cell via receptor ligand processes (Figure 2). Some of them are discussed below and which can also be used for targeting of herbal drugs to liver.

Different methods for coupling of ligand molecule on drug delivery system (Figure 3) are

(a) coupling of targeting moieties on preformed nanocarriers,

(b) coupling of targeting moieties by the post-insertion method,

(c) coupling of targeting moieties by the Avidin/Biotin complex,

(d) coupling of targeting moieties before nanocarriers formulation.

4.1.1. Coupling of Targeting Moieties on Preformed Nanocarriers. The design of nanocarriers possessing targeting moieties on their surface can be realized by coupling of the selected molecule to the surface of preformed nanocarriers using various methods of the coupling chemistry domain. Considerable amount of work has been done on the coupling of antibodies on the surface of preformed nanocarriers using maleimide groups located on their surface. Sugars have been 


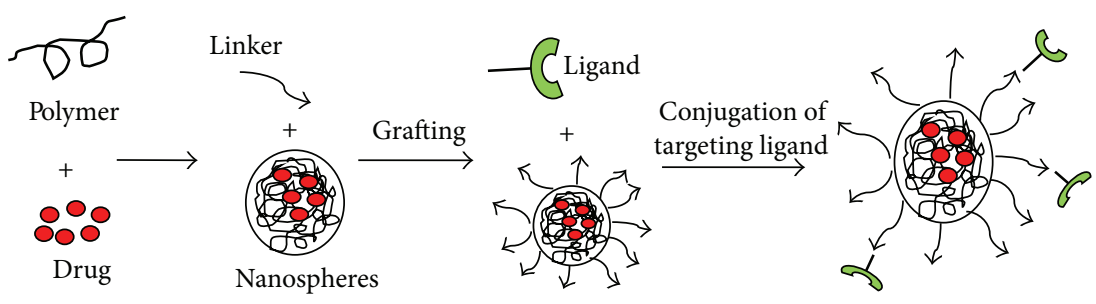

(a)

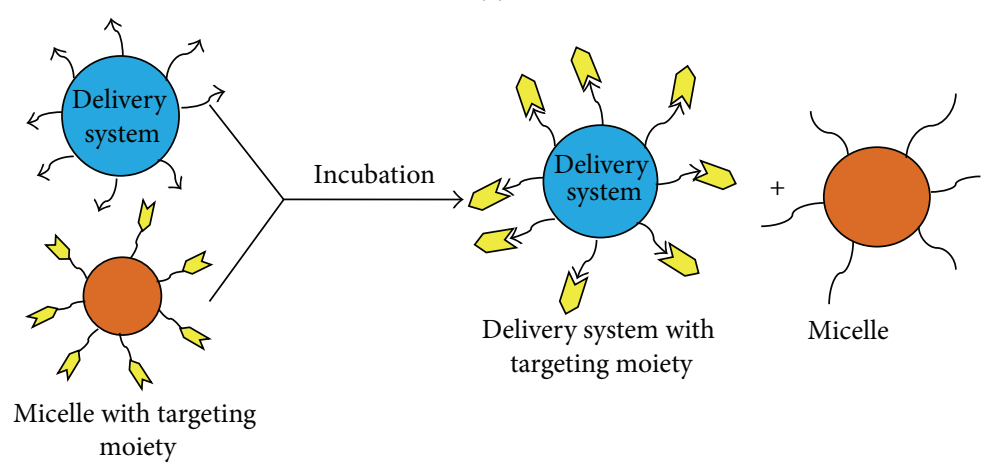

(b)

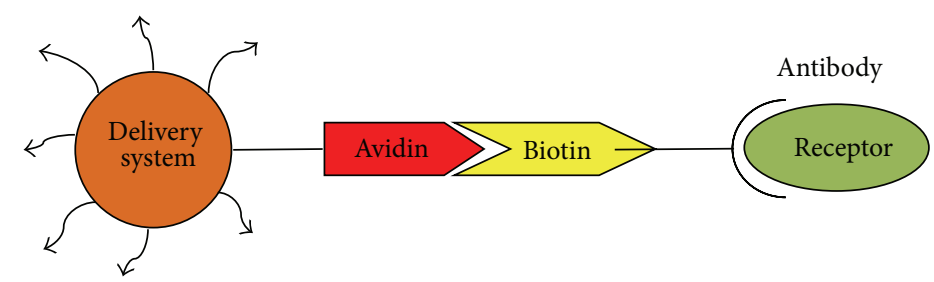

(c)

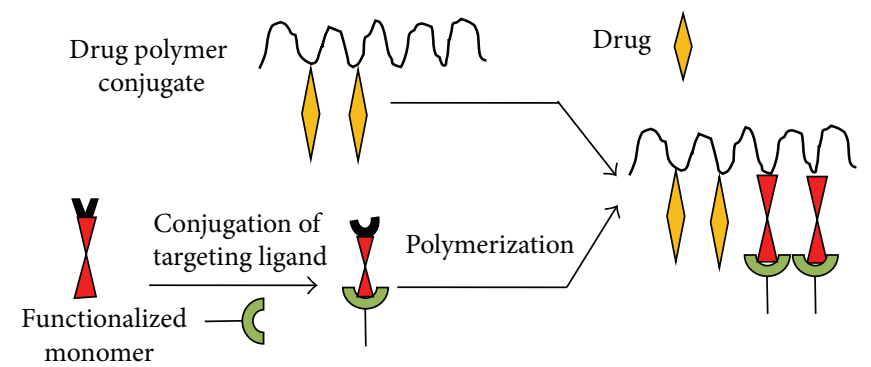

(d)

FIGURE 3: Different methods for coupling of ligand molecule on drug delivery system: (a) Coupling of targeting moieties on preformed nanocarriers. (b) Coupling of targeting moieties by the post insertion method. (c) Coupling of targeting moieties by the Avidin/Biotin complex. (d) Coupling of targeting moieties before nanocarriers formulation.

also widely used as targeting moieties. Liang et al. [26] have prepared nanoparticles composed of (PGA-PLA) processing galactosamide on their surfaces. Cellular uptake study, using rhodamine-123 loaded PGA-PLA nanoparticle with conjugated galactosamine, indicated that galactosylated nanoparticles had a specific interaction with HepG2 cells via ligandreceptor (ASGP-R) recognition. Viability of HepG2 cells treated with different paclitaxel formulations showed that the activity inhibiting the growth of cells by paclitaxel loaded galactosylated PGA-PLA nanoparticles was comparable to that of clinically available paclitaxel (Phyxol@) while paclitaxel loaded PGA-PLA nanoparticles displayed a significantly lower activity. The authors concluded that the galactosylated nanoparticles interacted in a specific manner with HepG2 cells via a ligand-receptor (ASGP-R) recognition leading to internalization of the drug carrier into HepG2 cells and release of paclitaxel into the cytoplasm. Biodistributions of the prepared nanoparticles in organs of normal mice and hepatoma bearing nude mice showed that galactosylated nanoparticles had specific interactions with liver's parenchymal cells and HepG2 cells via ligand receptor recognition. In addition, antitumor efficacy of the prepared nanoparticles on hepatoma bearing nude mice showed that paclitaxel loaded galactosylated PGA-PLA nanoparticles have the higher efficacy in reducing the tumor size. The results led the authors to conclude that paclitaxel (TX) loaded galactosylated 
PGA-PLA nanoparticles were mainly accumulated at the tumor site and the liver, in contrast to a nonspecific accumulation of Phyxol@.

Gupta et al. [27] reported that PLGA nanoparticles bearing HBsAg were prepared by double emulsion method and furthermore lectin from Arachis hypogaea (peanut agglutinin) was anchored onto the surface of the HBsAg loaded nanoparticles in order to enhance their affinity towards the antigen presenting cells of the Peyer's patches. They concluded that the ligand-coupled nanoparticles demonstrated approximately fourfolds increase in degree of interaction with the bovine submaxillary mucin (BSM) as compared to plain nanoparticles.

In another study, Bibby et al. [28] reported the bio-distribution and pharmacokinetics of a cyclic RGD-doxorubicinnanoparticle (NP) formulation in tumor-bearing mice. The NP core was composed of insulin multimethacrylate with a targeting peptide, cyclic RGD, covalently attached to the NPs via PEG-400 and revealed decreasing drug concentrations over time in the heart, lung, kidney, and plasma and accumulating drug concentrations in the liver, spleen, and tumor due to drug-receptor interaction as particle largely composed of carbohydrate, the insulin derivative, that is, insulin multimethacrylate (IMMA).

Stella et al. [29] studied the design of poly(ethylene glycol) (PEG)-coated biodegradable nanoparticles coupled to folic acid to target the folate-binding protein. In this study, preformed nanoparticles were conjugated to the activated folic acid via PEG terminal amino groups and purified from unreacted products and the authors concluded that folatelinked nanoparticles represent a potential new drug carrier for tumor cell-selective targeting.

Coupling of a targeting moiety on the surface of preformed nanocarriers has brought a significant improvement in the designing of targeted drug delivery systems.

\subsubsection{Coupling of Targeting Moieties by the Post-Insertion} Method. The modifications of preformed nanocarriers do not always lead to a controlled amount of bound targeting moieties, so other ways of coupling have been studied and the most important one is post-insertion method. The postinsertion technique seems to be relatively simple, leads to an appropriate level of stable ligand incorporation, and is not compromising for drug loading efficacy and drug release profile [30]. The post-insertion consists of firstly preparing the drug delivery system loaded with the selected drug, parallely micelles based on a mixture of functionalized PEG-lipid are prepared, and the selected targeting moiety is coupled to it. Secondly, the targeting moiety is transferred from micelles to drug delivery system by incubating both formulations. The post-insertion technique seems to be simple and leads to the expected site specific drug nanocarriers. However, number of targeting moieties on carrier surface was not always well defined and a drug leakage was observed during the incubation procedure.

Iden and Allen [31] prepared the stealth immunoliposomes (SIL) coupled to anti-CD19 by the post-insertion technique and revealed that the in vitro binding and uptake of PIL[anti-CD19] by CD19-expressing B-cell lymphoma
(Namalwa) cells were similar to those of SIL[anti-CD19] and both were significantly higher than binding of non-targeted liposomes (SL). In addition, no significant differences were found between the respective in vitro cytotoxicities of doxorubicin-loaded PIL [anti-CD19] or SIL[anti-CD19], or in their in vivo therapeutic efficacy in a murine model of human $\mathrm{B}$ lymphoma. Overall, the results demonstrate that the postinsertion technique is simple, flexible and effective means for preparing targeted liposomal formulations for clinical applications.

4.1.3. Coupling of Targeting Moieties by the Avidin/Biotin Complex. Avidin is a basic glycoprotein (MW $68 \mathrm{Kd}$ ) which has a high affinity for the small (MW $24 \mathrm{Kd}$ ) water soluble vitamin biotin. Biotin can be conjugated to a variety of biological molecules, including antibodies, and many biotin molecules can be attached to a single molecule of protein. The biotinylated protein can thus bind to more than one molecule of avidin. The strong avidin-biotin complex has been used to couple targeting moieties on nanocarrier's surfaces with the advantage that no coupling chemistry is normally needed. Bio-distribution of lactosyl-streptavidin (Lac-St, $5 \mathrm{~mol}$ $\mathrm{Lac} / \mathrm{mol} \mathrm{St}$ ), examined during period of several days, showed rapid uptake by the liver and almost none by blood and other tissues. Avidin and streptavidin were further subjected to an array of chemical modifications in an attempt to identify other tissue specificities. Chemical modification of lysine residues with trinitrophenyl (TNP) groups was found to abolish streptavidin accumulation in the kidney and led to specific and long-term accumulation in the liver [32].

Ouchi et al. [33] reported that the complexes prepared by mixing Biotin-triethyleneglycol-galactose (Bio-TEG-Gal) conjugate and fluorescein isothiocyanate (FITC)-labeled Av (feed molar ratio $4: 1$ ) and mixing Bio-TEG-Gal conjugate, Bio-TEG-TAMRA conjugate, and FITC-labeled Av are internalized into the hepatoma cells through a receptor-mediated endocytosis mechanism. Similarly, Mamede et al. [34] reported that the avidin-biotin system seems to have potential as a carrier of oligo-DNA to the liver. Zeng et al. [35] reported the synthesis of disulfide-containing polyethylenimine (PEISS) from low molecular weight branched PEI and cystamine bisacrylamide (CBA) and then grafted with biotin. The obtained biotinylated PEI-SS was bioconjugated with avidin via the biotin-avidin interaction to form a novel gene vector, biotinylated PEI-SS/avidin bio conjugate (ABP-SS). The results confirmed that ABP-SS contributes to more cellular uptake of complexes in HepG2 cells. Recently, Marysael et al. [36], as an alternative to directly targeting of necrotic tissue using hypericin, synthesized a conjugate of hypericin to biotin for use in a pretargeting approach. Hypericin was conjugated to biotin-ethylenediamine in a straightforward coupling method using n-hydroxysuccinimide and dicyclohexylcarbodiimide. It was concluded from analysis of autoradiography images which show a higher accumulation of I-avidin in pretargeted compared to non-targeted tissue.

4.1.4. Coupling of Targeting Moieties before Nanocarriers Formulation. Another efficient method for the introduction of targeting moieties consists of coupling the selected molecule 
at one end of a lipid or a polymer. Such strategy can be interesting because the coupling chemistry is realized on lipid or polymer. Moreover, a better control of amount of targeting moieties on nanocarrier surface can be reached, in theory, by introducing a well-defined mol\% of targeting moiety bearing a lipid or polymer in the formulation. In contrast to other methods, firstly the targeting moiety is attached to polymer at one of its ends and after that the drug is encapsulated in polymer coupled with ligand molecule. In this method, the chances of leakage of drug molecule is very less as ligand is coupled to polymer before the encapsulation process. By reviewing various literatures, galactose has been used for selective delivery of various drugs encapsulated in nanoparticles using different polymers. Wang et al. [37] prepared liposomes encapsulating doxorubicin and found that doxorubicin loaded galactosylated liposomes presented a high liver accumulation in comparison to doxorubicin loaded conventional liposomes with a loading efficiency of more than 95\%. Such high loading efficiency was attributed to positive charge and retention capacity of doxorubicin. Furthermore, the result of intrahepatic distribution and competitive inhibition study also confirmed that galactose residues of doxorubicin loaded galactosylated liposomes could be recognized by ASGP-R on the surface of parenchymal cells leading to high liver accumulation of such targeted liposomes. Jeong et al. [38] synthesized the poly(gamma-benzyl L-glutamate) (PBLG)/poly(ethylene glycol) (PEG) diblock copolymer endcapped with galactose moiety and characterized for study of liver specific targeting and concluded that HepG2 cells with ASGP-R are more sensitive to TX-loaded nanoparticles than free TX, whereas P388 cells, murine leukemia cell line, and SK-Hep 01, human hepatoma cell line, without ASGP-R are less sensitive to TXloaded nanoparticles than free TX, suggesting that specific interaction between HepG 2 cells and galactose moiety of the nanoparticles occurred.

Hattori et al. [39] investigated the potency of the mannosylated cationic liposomes (Man liposomes) and suggested that the targeted delivery of DNA vaccine by Man liposomes is a potent vaccination method for DNA vaccine therapy. Opanasopit et al. [40] reported that muramyl dipeptide (MDP) can be selectively targeted to liver non-parenchymal cell (NPC), including Kupffer cell (KC) using mannosylatedliposomes. Tian et al. [41] firstly modified the chitosan polymer with glycyrrhetinic acid and then prepared the nanoparticles of BSA and concluded that BSA could be entrapped into the nanoparticles with the drug-loading ratio of $26.3 \%$ and the encapsulation efficiency of $81.5 \%$. A sustained release over 11-day period was observed in $\mathrm{pH} 7.4$ in vitro. Recently, Tian et al. [42] showed that the CTS/PEG-GA nanoparticles were remarkably targeted to the liver and maintained high concentration of drug for prolonged period of time.

\section{Novel Materials/Ligands Used for Liver Targeting}

Different hepatic diseases involve different cells (namely, hepatocytes, Kupffer cell, hepatic stellate cell and sinusoidal endothelial cells, hepatic carcinoma cell, etc.). Hence, it is important to design or select proper materials to target these different diseased cells. In this section, various novel materials used to enhance the targeting efficiency of drug delivery systems to receptors in the liver have been discussed with appropriate cases.

\subsection{Hepatic Parenchymal Cell Targeting Materials}

5.1.1. Asialoglycoprotein Receptor (ASGP-R) Targeting Materials. This receptor is responsible for the clearance of glycoproteins with desialylated galactose or acetylgalactosamine residues from the circulation by receptor-mediated endocytosis.

Galactose Ligand. Galactosylated surface is an attractive substrate for hepatocyte culture because of the specific interaction between the galactose ligand and the asialoglycoprotein receptor on hepatocytes. The density of galactose is one of the important parameters for the hepatocyte attachment as it is a major determinant of the hepatocyte attachment, morphology, and functions, as reported by Ashwell and Harford [43]; a multisubunit receptor of hepatocytes is responsible for binding galactose residues on desialylated glycoproteins and triantennary molecules that bind to the lectin with higher affinity than oligosaccharides lacking a third branch [44].

Kobayashi et al. [45] investigated the effects of galactose densities in the galactose carrying PS derivative on morphology, differentiation, and proliferation of hepatocytes. The results indicated that hepatocytes exhibited lower $3 \mathrm{H}$ thymidine uptake under the round morphology on the higher galactose density and higher $3 \mathrm{H}$-thymidine uptake under the spread morphology on the lower galactose density. Ise et al. reported that hepatocytes attached to galactose carrying PS below $20 \mathrm{ng} / \mathrm{mL}$ coating density expressed low levels of ASGP-R and exhibited higher proliferative capacities than above $50 \mathrm{ng} / \mathrm{mL}$ coating density [46].

The galactose ligand-ASGP-R interaction is not only influenced by the ligand density on the ECM but also by the spatial orientation of the ligand. Cho et al. [47] investigated the effect of galactose orientation on the attachment of hepatocyte to galactose carrying PS surface prepared by the Langmuir-Blodgett (LB) technique. It was found that the hepatocytes cultured on LB surface of the polymer even at the low galactose concentration could well recognize galactose moieties of the polymer owing to the galactose orientation, suggesting that the spatial microdistribution of the galactose in the ECM is important for the regulation of the cell adhesion.

Lactoferrin $(L f)$. It is a mammalian cationic iron binding glycoprotein belonging Lactoferrin (Lf), a mammalian cationic iron-binding glycoprotein belonging to the transferrin (Tf) family [48], recently became increasingly attractive because of its multifunctional and mediating biological activities with Lf receptors (Lf-R) $[49,50]$. Formerly Lf-R was successfully utilized as a targeting ligand for brain delivery due to the presence of Lf receptor on blood brain barrier (BBB) [51, 52]. Likewise, many recent studies revealed that lactoferrin could bind to multiple receptors on hepatocytes. For instance, 
Wei et al. reported Lf-PEGylated liposomes (PLS) as a promising drug delivery system for hepatocellular carcinoma therapy with lower toxicity and enhanced efficacy [53-56]. It has been validated that Lf-R binds to ASGP-R with high affinity $[57,58]$, implying that Lf-R is a good ligand to ASGP$\mathrm{R}$ binding. With its specific binding, Lf- $\mathrm{R}$ has been applied to gene delivery successfully, transferring genetic material to the hepatocytes [59]. These exciting evidences suggested that Lf-R might be a promising candidate for hepatocellular carcinoma targeting due to its high affinity for ASGP-R, and developing a hepatic carcinoma targeting drug delivery system employing the ASGP-R targeting ability of Lf-R is highly possible.

Lacto Bionic Acid (LA) Ligand. Kamruzzaman Selim et al. [60] synthesized super paramagnetic magnetite nanoparticles which were surface modified with lactobionic acid (LA) to improve their intracellular uptake and ability to target hepatocytes and reported that LA-modified magnetite nanoparticles have a great potential to be used as contrast agent for liver diagnosis. Later in 2009 [61] beta-galactose carrying lactobionic acid (LA) was conjugated on the surface of mercaptoacetic acid coated cadmium sulfide nanoparticles (CSNPs) to ensure specific recognition of liver cells (hepatocytes) and to enhance biocompatibility and found that the uptake amount of Lactobionic Acid-immobilized CSNPs into hepatocytes was higher than that of CSNPs and Maltotrionic acidCSNPs.

Asialofetuin (AF) Ligand. AF, a natural ligand, is a glycoprotein that possesses three asparagine-linked triantennary complex carbohydrate chains with terminal LacNAc (N-acetyllactosamine) residues. The expressed protein displays affinity to hepatocyte ASGP-R and is endocytosized by the cells. Its receptor dissociation constant is 200 -fold lower than the glycoproteins with biantennary $\mathrm{N}$-linked oligosaccharide chains. Therefore, it has been used as a competitive inhibitor to other polysaccharides that also have affinity to the receptors. Díez et al. [62] synthesized cationic nanoparticles using $\mathrm{AF}$ as ligand and concluded that targeted-NP2 particles showed a 5- and 12-fold higher transfection activity in the liver compared to non-targeted (plain) complexes.

Soybean-Derived SG Ligand. Soybean-derived SG is a residue extracted from soybeans. Maitani et al. [63] investigated the interaction of liposomes surface-modified with soybeanderived sterylglucoside (SG) (SG-liposomes) with HepG2 cells and concluded that SG-liposomes are potentially useful drug carriers to target the liver, because the glucose residue may work as a kind of ligand for ASGP-R. Qi et al. [64] studied hepatocyte-specific targeting technology by modifying cationic liposomes with soybean sterylglucoside (SG) and polyethylene glycol and found that C/SG/PEG-liposomes mediated gene transfer to the liver was an effective genedelivery method for hepatocytes-specific targeting, which appears to have a potential for gene therapy of HBV infections. Later on, Shi et al. [65] constructed a liposomal liver targeting delivery system by adding soybean-derived sterylglucoside (SG) to the cationic liposomes and concluded that
SG/Brij-35 modified cationic liposomes are potentially useful drug carrier to the liver.

5.1.2. Glycyrrhetinic Acid (GA) Receptor Targeting Materials. Glycyrrhizin (GL) and glycyrrhetinic acid (GA) are the main bioactive compounds of licorice and are widely used in medicine for the treatment of many pathologies [16, 17], such as antiinflammatory, antigastric, antihepatitis, antiallergic and antihepatotoxic effects. Negishi et al. [66] showed that there are specific binding sites for GL and GA on the cellular membrane of rat hepatocytes and confirm that the number of binding sites for GA is much more than that for GL. Recently, Wolfrum et al. [19] prepared chitosan nanoparticles modified with glycyrrhizin (CTS-NPs-GL) and confirmed that CTSNPs-GL preferentially accumulated in the rat hepatocytes by a ligand receptor interaction. Akinc et al. [20] also found that the cellular uptake of liposomes modified with glycyrrhetinic acid by rat hepatocytes was 3.3-fold higher than that of unmodified ones. Although the liver cell targeting ability of the GA-modified polymers has been confirmed in vitro, there are no reports on the distribution of GA-modified materials in vivo and on the presence of GA receptors on human hepatic cells. Therefore, it is necessary to investigate the distribution of GA modified carriers in vivo and their affinity for human liver cells. These studies would be of immense importance for the development of GA mediated liver-targeted drug delivery.

5.1.3. Bile Acid Receptor Targeting Materials. Bile acids and bile acid receptors are therapeutic targets in the development of drugs for the treatment of cholestatic and fatty liver diseases. Clerc et al. [67] determine the effect of exogenous unesterified cholesterol provided in either artificial liposomes or LDL on bile salt and they concluded that taurocholate increased the exchange of cholesterol between liposomes or LDL and hepatocyte membranes. Pütz et al. [68] examine the possibility of targeting liposomes to hepatocytes via bile salts; the bile salt lithocholyltaurine was covalently linked to a phospholipid and concluded that the attachment of bile salts to the surface of hepatocytes opens up promising possibilities for hepatocyte-specific drug delivery.

\subsection{Hepatic Non-Parenchymal Cell Targeting Materials}

5.2.1. Mannose Receptor Targeting Materials. Mannose receptors are known to contribute to the defense mechanism of mammals by endocytosis or phagocytosis of terminal mannose bearing exogenous materials. Mannose, a sugar monomer of hexose, has several important biological roles, including the glycosylation of proteins. Unlike galactose interactions with asialoglycoprotein receptors on parenchymal liver cells, D-mannose is recognized by mannose receptor generally present on non-parenchymal liver cells such as Kupffer cells, macrophages resident in the liver. A mannose 6-phosphate binding protein with a subunit and molecular size of 215,000 has been isolated from bovine liver. The expression of mannose-6-phosphate on rat hepatic stellate cell is increased during liver fibrosis [69]. 
Jayasree et al. [70] has prepared mannosylated chitosanzinc sulphide nanocrystals and reported that prepared nanobioconjugates through simple aqueous chemistry possessed high colloidal stability and strong fluorescence emission at $\sim 600 \mathrm{~nm}$. Characterization using X-ray diffraction, dynamic light scattering, scanning electron microscope, atomic force microscopy, and Fourier transformed infrared spectroscopy revealed that the bioconjugated particles were appropriately functionalized and stable, with an average size of $150 \mathrm{~nm}$. Bioconjugation with mannose provided specificity and targeted cellular labelling characteristics as demonstrated using $\mathrm{KB}$ cells which overexpress mannose receptors on their surface.

Rieger et al. [71] reported biodegradable polymeric nanoparticles presented with mannose residue at their surface and their interaction with lectins. The study concluded that prepared nanoparticles are expected to be specifically recognized by mannose receptors which are highly expressed in cells of the immune system. The targeting properties of these carrier systems combined with their potential adjuvant effects due to their size in the range of $200-300 \mathrm{~nm}$ make them attractive candidates as vaccine delivery systems.

Kawakami et al. [72] synthesized novel mannosylated cholesterol derivative, cholesten-5-yloxy-N-(4-((1-imino-2beta-D-thiomannosyl-ethyl)amino)butyl) formamide (ManC4-Chol), in order to perform mannose receptor mediated gene transfer with liposomes. The results reported by them suggest that plasmid DNA complexed with mannosylated liposomes exhibits high transfection activity due to recognition by mannose receptors both in vitro and in vivo.

5.2.2. Hepatic Stellate Cell (HSC) Targeting Materials. HSCs play a central role in the progression of liver fibrosis. Muriel et al. [73] investigate a suitable model of fibrosis, in which spontaneous reversion was minimal, in order to study the ability of silymarin, silibinin, colchicine, and trimethylcolchicinic acid (TMCA) to reverse it and the model reported by them was proved to be an excellent tool to study the ability of drugs to reverse fibrosis. Suojanen et al. [74] studied the tumour growth and lymphatic micrometastatic by use of HSC-3cell xenografted athymic nude mice and concluded that peptide gelatinase inhibitors are effective in inhibiting primary tumor growth but alone they do not prevent the spread of carcinoma cells. Table 2 provides compilation of different targeting ligands employed for enhanced liver targeting.

\section{Targeting Strategies for Different Constituent Cells of Liver and Their Implications}

The approaches to drug targeting described so far are not universal. Direct administration of a drug into an affected organ or tissue may be technically difficult. Often, the affected areas do not differ much from the normal tissues in terms of vascular permeability, temperature, and local $\mathrm{pH}$ value. Magnetic drug delivery also has limitations connected with blood flow rate in the target. The most natural and universal way to impart the affinity toward the target to a nonspecific drug is the binding of this drug with another molecule (targeting moiety) capable of specific recognition and binding at the target site. The following substances can be used as targeting moieties: antibodies and their fragments, lectins, other proteins, lipoproteins, hormones, charged molecules, mono-, oligo- and polysaccharides, and some low molecular weight ligand such as sugars, folic acids, and peptides. The parameters that determine the efficacy of drug targeting include the size of target, blood flow through the target, number of binding sites for the targeted drug/drug carrier within the target, number and affinity of targeting moieties on a drug molecule, and multipoint interaction of a drug/drug carrier with the target [88]. Targeting moiety should be selected by keeping the following points in mind: (i) reaction between carrier and moiety has to be simple, fast, efficient, and reproducible, (ii) coupling method has to yield to stable and nontoxic bond, (iii) target recognition and binding efficiency of the coupled molecule have to be maintained, (iv) targeted nanocarriers have to be stable enough to present a circulation half-life allowing them to reach and interact with their site of action, and finally (v) both the drug loading efficiency and the drug release profile do not have to be significantly changed by targeting moieties coupling reactions.

6.1. Liver Cell Specific Targeting of Therapeutics. Carrier molecules are designed for selective cellular uptake, taking advantage of specific receptors or binding sites present on the surface membrane of the target cell (Table 1). In various literatures, hepatocytes targeting is synonymous for liver targeting and total liver uptake of a compound is measured without proper identification of the cell type that actually takes up the drug. Although hepatocytes represent more than $80 \%$ of the total number of resident hepatic cells, uptake in other cell types like Kupffer cells may occur as well and high uptake of viruses, antibodies, or other biological compounds into these cells often leads to complete degradation of such compounds, which in some cases destroys their therapeutic activity [13]. Therefore, for specific cell, there should be specific delivery system and ligand for targeting. There may be five different cells types present in liver for active targeting of drug, namely, (i) hepatocytes, (ii) Kupffer and sinusoidal endothelial cells, (iii) hepatic stellate cells (HSC), (iv) bile duct epithelial cells, and (v) hepatocellular carcinoma cells. Table 3 provides details of targeting approaches of drugs for different constituent cells of liver.

6.1.1. Hepatocytes. Hepatocytes are generally the affected site in various liver diseases like viral hepatitis (hepatitis A, B, or C), alcohol-induced steatohepatitis (ASH), nonalcoholinduced steatohepatitis (NASH), and some genetic diseases like Wilson's disease, hemochromatosis, $\alpha$-1 antitrypsin deficiency, and several other metabolic disorders. In order to reduce the side effect and enhance the therapeutic effect of drugs, many methods for hepatocytes selective drug targeting have been used in the past decades. The most prevalent and the effective strategies for targeting hepatocytes are mentioned below.

Asialoglycoprotein receptors (ASGP-R) are exclusively found in hepatocytes located at the basolateral membrane 
TABle 2: Different ligand-based liver targeting approaches and conclusions.

\begin{tabular}{|c|c|c|c|}
\hline Drug & Ligand & Conclusion & References \\
\hline Doxorubicin & Galactosamine & $\begin{array}{l}\text { GAL-DOX-AN is more effective in killing HepG } 2 \text { cell } \\
\text { than DOX-AN }\end{array}$ & {$[75]$} \\
\hline Sugar charge-modified albumins & Lactose, mannose & $\begin{array}{l}\text { Study demonstrates that cell-specific delivery of sugar- } \\
\text { and charge-modified albumins in fibrotic livers is } \\
\text { possible by coupling drugs to lactose and mannose }\end{array}$ & {$[76]$} \\
\hline $\begin{array}{l}5 \text {-Iodo } 2^{\prime} \text {-deoxyuridine } \\
5^{\prime} \text {-monophosphate }\end{array}$ & Lactose & $\begin{array}{l}\text { Bioavailability of } 5 \text {-iodo } 2^{\prime} \text {-deoxyuridine } \\
5^{\prime} \text {-monophosphate to the parenchymal liver cell is } \\
\text { dramatically enhanced as a result of the conjugation of } \\
\text { the antiviral drugs to lactosylated poly-L-lysine }\end{array}$ & {$[31,77]$} \\
\hline Dextran & $\begin{array}{l}\text { Permanent magnets and } \\
\text { calcein as a fluorescent } \\
\text { marker }\end{array}$ & $\begin{array}{l}\text { Dextran magnetite (DM)-incorporated thermosensitive } \\
\text { liposomes would be useful in future cancer treatment } \\
\text { by magnetic targeting combined with drug release in } \\
\text { response to hyperthermia }\end{array}$ & {$[78]$} \\
\hline $\begin{array}{l}\text { Tyr }^{3} \text {-octreotide (TOC), a somatostatin } \\
\text { analogue }\end{array}$ & $\begin{array}{l}N \text {-palmitoyl cysteinyl } \\
\text { moiety }\end{array}$ & $\begin{array}{l}\text { Tyr }{ }^{3} \text {-octreotide (TOC), a somatostatin analogue shows } \\
\text { enhanced therapeutic efficacy due to the liver-targeting } \\
\text { effect when coupled with } N \text {-palmitoyl cysteinyl moiety. }\end{array}$ & [79] \\
\hline $\begin{array}{l}\text { Methotrexate conjugated with bovine } \\
\text { serum albumin (BSA) }\end{array}$ & Galactose & $\begin{array}{l}\text { Galactosylation of the carrier protein BSA significantly } \\
\text { enhanced the hepatocytes uptake and liver targetability } \\
\text { of MTX }\end{array}$ & {$[80]$} \\
\hline $\begin{array}{l}\text { Prednisone acetate conjugated with } \\
\text { polycaprolactone-g-dextran polymer }\end{array}$ & $\begin{array}{l}\text { Galactose and fluorescein } \\
\text { isothiocyanate }\end{array}$ & $\begin{array}{l}\text { In vivo study indicated potential of prednisone acetate } \\
\text { loaded galactosylated micelles in liver targeting }\end{array}$ & {$[81]$} \\
\hline Lactobionic conjugated with chitosan & $\begin{array}{l}\text { Azide }(\mathrm{CHI}-\mathrm{Az}) \text { or alkyne } \\
\text { (CHI-Alk) groups }\end{array}$ & $\begin{array}{l}\text { Lactobionic acid was conjugated with } \\
\text { (CHI-Az/CHI-Alk)-coated particles and the particles } \\
\text { exhibited hepatoma cell (HepG2) targeting behavior }\end{array}$ & {$[82]$} \\
\hline Doxorubicin & $\begin{array}{l}\text { Soybean-derived } \\
\text { sterylglucoside (SG) }\end{array}$ & $\begin{array}{l}\text { SG liposomes are potentially useful drug carriers to the } \\
\text { liver, because the glucose residue may work as a kind of } \\
\text { ligand for asialoglycoprotein receptor (ASGP-R) on } \\
\text { hepatocytes }\end{array}$ & {$[63]$} \\
\hline $\begin{array}{l}\text { Primaquine phosphate conjugated } \\
\text { with polypropyleneimine (PPI) } \\
\text { dendrimers }\end{array}$ & $\begin{array}{l}\text { Coated peripherally with } \\
\text { galactose }\end{array}$ & $\begin{array}{l}\text { The galactose coating of PPI dendrimers can make the } \\
\text { PPI systems more effective and suitable for targeted } \\
\text { delivery of primaquine phosphate to liver }\end{array}$ & {$[83]$} \\
\hline Paclitaxel conjugated with PLGA & Galactose & $\begin{array}{l}\text { Paclitaxel loaded galactosylated PGA-PLA } \\
\text { nanoparticles were mainly accumulated at the tumor } \\
\text { site and the liver }\end{array}$ & {$[84]$} \\
\hline Rhein & $\begin{array}{l}\text { Vinegar-baked Radix } \\
\text { Bupleuri }\end{array}$ & $\begin{array}{l}\text { Co-administration of rhein with VBRB efficient for } \\
\text { liver targeting }\end{array}$ & {$[85]$} \\
\hline Streptavidin & $\begin{array}{l}\text { Trinitrophenyl (TNP) } \\
\text { groups }\end{array}$ & $\begin{array}{l}\text { The modified proteins could target high doses of } \\
\text { chemotherapeutic drugs (CDDP and 5-fluorouridine) } \\
\text { to the liver through biotinyl dextran-derived carriers }\end{array}$ & {$[86]$} \\
\hline $\begin{array}{l}\text { 5-Fluoro 29-deoxyuridine conjugated } \\
\text { with lactosaminated poly-L-lysine }\end{array}$ & Lactose & $\begin{array}{l}\text { Poly-L-lysine-5-fluoro-2'-deoxyuridine enters into } \\
\text { HepG2 cells through the asialoglycoprotein receptor } \\
\text { and, after intracellular penetration, releases the drug in } \\
\text { a pharmacologically active form }\end{array}$ & {$[87]$} \\
\hline
\end{tabular}

and therefore are in direct contact with the bloodstream. The human ASGP-R is a heterooligomer that is composed of two homologous subunits (46 and $50 \mathrm{kDa}$ ). ASGP-R recognizes with high affinity (KD in the nanomolar range) tri- and tetraantennary $\mathrm{N}$-linked sugar side chains with terminal galactose residues [109]. Therefore, galactose residue $[17,110]$ or lactose moieties [111] act as ligand and are coupled to proteins polymers or incorporated into the outer layer of delivery system by one of the methods described above [16]. Glycoproteins with such glycosylation patterns are rapidly endocytosed by the ASGP-R via clathrin-coated pits and vesicles. In a similar context, Shinoda et al. [112] investigate specific interaction 
TABLE 3: Cell specific hepatic targeting of different drugs.

\begin{tabular}{|c|c|c|c|}
\hline Type of cell/receptor & Drug & Further remarks & References \\
\hline $\begin{array}{l}\text { Hepatocytes and } \\
\text { asialoglycoprotein } \\
\text { receptor }\end{array}$ & Iododeoxyuridine (IDU) & $\begin{array}{l}\text { By isolating liver cells after injection of the } \\
\text { iododeoxyuridine (IDU), it was concluded that } \\
\text { hepatic uptake occurred mainly in } \\
\text { parenchymal liver cells }\end{array}$ & {$[89]$} \\
\hline Hepatocytes & Primaquine (PQ) & $\begin{array}{l}\text { The prepared emulsion could be developed } \\
\text { into a promising delivery system to target PQ } \\
\text { into hepatocytes for vivax malaria therapy }\end{array}$ & {$[90]$} \\
\hline Hepatocytes & 5-Fluorouracil (5-FU) & $\begin{array}{l}\text { The drug-loaded } \mathrm{ZPs}^{*} \text { could be efficiently } \\
\text { targeted at the liver by intravenous delivery }\end{array}$ & {$[91]$} \\
\hline $\begin{array}{l}\text { Hepatic stellate cell } \\
\text { (HSC) }\end{array}$ & $\begin{array}{l}\text { Human serum albumin (HAS) modified with } \\
\text { mannose6-phosphate (M6P) }\end{array}$ & $\begin{array}{l}\text { M6P-modified albumins are taken up by HSC } \\
\text { in fibrotic livers }\end{array}$ & {$[92]$} \\
\hline $\begin{array}{l}\text { Hepatic stellate cell } \\
\text { (HSC) }\end{array}$ & MicroRNAs & $\begin{array}{l}\text { The study shows that there was direct target of } \\
\text { miR-181b in HSC-T6 cell }\end{array}$ & {$[93]$} \\
\hline $\begin{array}{l}\text { Hepatic stellate cell } \\
\text { (HSC) }\end{array}$ & Antibody fragment & $\begin{array}{l}\text { This antibody fragment may be an effective } \\
\text { means to target therapeutics to human hepatic } \\
\text { stellate cells }\end{array}$ & {$[94]$} \\
\hline Hepatic carcinoma cell & $\begin{array}{l}\text { Glycyrrhetinic acid-modified poly(ethylene } \\
\text { glycol)-b-poly(c-benzyl L-glutamate) } \\
\text { (GA-PEG-PBLG) micelles }\end{array}$ & $\begin{array}{l}\text { In vitro cell uptake results indicated that the } \\
\text { introduction of GA to the micelles significantly } \\
\text { increased the affinity for human hepatic } \\
\text { carcinoma }\end{array}$ & {$[95]$} \\
\hline Hepatic carcinoma cells & Ribavirin nanoparticles & $\begin{array}{l}\text { The nanoparticles had effective growth } \\
\text { inhibitory activity in hepG2 human hepatoma } \\
\text { cells }\end{array}$ & {$[96]$} \\
\hline Hepatic carcinoma cell & Rhodamine B with lactose as ligand & $\begin{array}{l}\text { The Lac-micelles will be an effective } \\
\text { liver-targeting drug delivery system }\end{array}$ & {$[97]$} \\
\hline $\begin{array}{l}\text { Kupffer cell } \\
\text { (nonparenchymal cells) }\end{array}$ & $\begin{array}{l}\text { Cholesten-5-yloxy- } N \text {-(4-((1-imino-2-b-D- } \\
\text { thiomannosylethyl)amino)butyl)formamide } \\
\text { (Man-C4-Chol) into small unilamellar liposomes } \\
\text { consisting of cholesterol and distearoyl } 3 \\
\text { phosphatidylcholine (DSPC) }\end{array}$ & $\begin{array}{l}\text { The results suggest that Man liposomes are } \\
\text { effective carriers for targeted delivery of } \\
\text { bioactive compounds to liver NPC }\end{array}$ & {$[40]$} \\
\hline $\begin{array}{l}\text { Hepatic stellate cell } \\
\text { (HSC) }\end{array}$ & Pentoxifylline & $\begin{array}{l}\text { PTX-neoglycoprotein } \\
\text { mannose-6-phosphate-albumin (M6PHSA) } \\
\text { employing a novel type of platinum linker, } \\
\text { which allows sustained delivery of the drug to } \\
\text { HSC in the fibrotic liver }\end{array}$ & {$[98]$} \\
\hline Hepatocytes & $\begin{array}{l}\text { Galactosylated poly(ethylene } \\
\text { glycol)-chitosan-graft-polyethylenimine } \\
\text { (Gal-PEG-CHI-g-PEI) }\end{array}$ & $\begin{array}{l}\text { Together, these results suggest that } \\
\text { Gal-PEG-CHI-g-PEI, which has improved } \\
\text { transfection efficiency and hepatocytes } \\
\text { specificity both in vitro and in vivo, may be } \\
\text { useful for gene therapy }\end{array}$ & {$[99]$} \\
\hline $\begin{array}{l}\text { Hepatocytes } \\
\text { (asialoglycoprotein R) }\end{array}$ & $\begin{array}{l}\text { Vitamin K5 and cytosine arabinoside using } \\
\text { poly-L-glutamic acid and carboxymethyl dextran }\end{array}$ & Effective targeting to hepatocytes & {$[100]$} \\
\hline Hepatic carcinoma cells & $\begin{array}{l}\text { Ursodeoxycholic acid (UA) modified } \\
\text { protein-lipid nanocomplex }\end{array}$ & $\begin{array}{l}\text { The uptake of UA modified protein attached on } \\
\text { the nanoparticles was higher in hepatic } \\
\text { carcinoma cells (HepG2 and Bel 7402) than in } \\
\text { normal liver cells }\end{array}$ & {$[101]$} \\
\hline Hepatic carcinoma cell & $\begin{array}{l}\text { Human telomerase reverse transcriptase with } \\
\text { pegylated immuno-lipopolyplexes }\end{array}$ & $\begin{array}{l}\text { The vector pApoAI-shTERT was able to cause } \\
\text { liver-specific and hTERT target-specific } \\
\text { cytotoxicity, and utilizing PILP to deliver } \\
\text { pApoAI-shTERT is a promising strategy for } \\
\text { liver-specific gene therapy }\end{array}$ & {$[102]$} \\
\hline Nonparenchymal cells & $\begin{array}{l}\text { Mannosylated superoxide dismutase } \\
\text { (SOD) }\end{array}$ & $\begin{array}{l}\text { Increased delivery of SOD to nonparenchymal } \\
\text { cell }\end{array}$ & {$[103]$} \\
\hline Hepatocytes & Probucol liposomes & $\begin{array}{l}\text { Hepatic uptake of liposomes should be } \\
\text { mediated by asialoglycoprotein receptors being } \\
\text { probucol incorporated in them }\end{array}$ & {$[104]$} \\
\hline
\end{tabular}


TABLe 3: Continued.

\begin{tabular}{lll}
\hline Type of cell/receptor & Drug & Further remarks \\
\hline Endothelium cell & $\begin{array}{l}\text { Paclitaxel (PTX)-loaded PEGylated PLGA-based } \\
\text { nanoparticles grafted with RGD peptide }\end{array}$ & $\begin{array}{l}\text { The targeting of anticancer drug to tumor } \\
\text { endothelium by RGD-labeled NP is a } \\
\text { promising approach }\end{array}$ \\
\hline $\begin{array}{l}\text { Cyclic Arg-Gly-Asp (RGD) peptides were } \\
\text { (HSC) }\end{array}$ & $\begin{array}{l}\text { Targeted liposomes encapsulating HGF are a } \\
\text { promising therapeutic modality in terms of } \\
\text { promoting the remission of liver cirrhosis by } \\
\text { phomoting collagen fiber digestion, inhibiting } \\
\text { phosphothanolamine (MAL-PEG-DOPE) } \\
\text { incorporated into stabilized liposomes }\end{array}$ & $\begin{array}{l}\text { [106, 107] } \\
\text { of } \alpha \text {-SMA-positive cells in rats with cirrhosis }\end{array}$ \\
\hline $\begin{array}{l}\text { Hepatocytes } \\
\text { (asialoglycoprotein } \\
\text { receptor) }\end{array}$ & $\begin{array}{l}\text { Super paramagnetic iron oxide (SPIO) } \\
\text { nanoparticles }\end{array}$ & $\begin{array}{l}\text { These data underline the potential application } \\
\text { of Gal-ASPIO as a targeted ligand for } \\
\text { ASPGR-expressing cells in vivo }\end{array}$ \\
\hline & $\begin{array}{l}\text { Doxorubicin loaded super paramagnetic iron } \\
\text { oxide nanoparticles }\end{array}$ & $\begin{array}{l}\text { DOX is a promising candidate for treating liver } \\
\text { cancer and monitoring the progress of the } \\
\text { cancer using MRI }\end{array}$ \\
\hline
\end{tabular}

${ }^{*}$ Zein nanoparticles.

between galactose branched cyclodextrins (gal-CyDs) and hepatocytes in vitro and concluded that enzymatically synthesized gal-CyDs have specific interaction with the hepatocytes and may be useful as a drug targeting carrier to hepatocytes. But when efficient delivery of liposomes to hepatocytes was performed by targeting the galactose receptor on the surface of hepatocytes by lactosylceramide and asialofetuin then it was found that lactosylceramide containing vesicles distributed $48 \%$ in hepatocytes and $27 \%$ in non-parenchymal cells [113]. It has been shown that a galactose receptor is also located on Kupffer cells and involved in endocytosis or phagocytosis of particles with galactosyl residues [69]. These receptors are not evenly distributed on the surface of Kupffer cells but clustered for the uptake of particles [70]. However, the galactose receptors on hepatocytes are evenly distributed [71] and can uptake ligand of up to $8 \mathrm{~nm}$ in diameter [72]. Thus, galactose moiety to target asialoglycoprotein receptor may not be a good target for the selective delivery of liposomes to hepatocytes. Therefore, the discovery of new ligands for liver targeting, instead of the use of the conventional ligands, is very important. Another ligand for hepatocytes was investigated by Lin et al. [114] in which chitosan nanoparticles surface was modified with glycyrrhizin (CS-NPs-GL) as new hepatocyte-targeted delivery vehicles and concluded that CSNPs-GL could be a promising hepatocyte-targeted delivery carrier. But Negishi et al. [66] showed that the number of binding sites for glycyrrhetinic acid (GA) is much more than that for GL. Therefore, Tion et al. [115] prepared glycyrrhetinic acid-modified chitosan/poly(ethylene glycol) nanoparticles for liver-targeted delivery and found that the cellular uptake of nanoparticles modified with glycyrrhetinic acid by rat hepatocytes was 19-fold higher than that of unmodified ones. In fact delivery of NDDS (like liposomes, niosomes, nanoparticles, and phytosomes) and proteins to the hepatocytes using ASGP-R as a target receptor was one of the first options for the cell specific delivery to the liver cells although this has not led to any clinical application yet.
6.1.2. Kupffer and Sinusoidal Endothelial Cells. Kupffer and sinusoidal endothelial cells are localized within the space of disse in close vicinity of the hepatocytes [116]. Kupffer cells, the resident liver macrophages, have long been considered as scavenger cells responsible for removing particulate material from the portal circulation. However, evidence derived mostly from animal models indicates that Kupffer cells may be implicated in the pathogenesis of various liver diseases including viral hepatitis, steatohepatitis, alcoholic liver disease, intrahepatic cholestasis, and activation or rejection of the liver during liver transplantation and liver fibrosis [117]. Both the Kupffer and sinusoidal endothelial cells share many characteristics that can be relevant for the enhanced uptake of drug delivery systems by these cells. They are endowed with a high phagocytic capacity and are as such an intrinsic part of the reticuloendothelial system (RES). This system plays an essential role in the regulation of the host defence system and because of this, many foreign particles that accumulate in these two cell types [118]. Several of these diseases are treated with systemic immunosuppressive agents, but there are many arguments that favour a local downregulation of inflammatory processes within the liver rather than inducing systemic immunosuppressive effects [119]. Accumulation of therapeutic compounds in Kupffer and endothelial cells can either be nonspecific or specific via designated receptors. Drug delivery systems like liposomes, micelles and viral particles end up in these cells via nonspecific uptake mechanisms due to their largest phagocytic activity [120].

In addition, uptake in Kupffer and endothelial cells can also be mediated by specific receptors. These cells bind to negatively charged molecules via scavenger receptors that are abundantly expressed on their membrane $[121,122]$; for example, coupling of compound to lysine groups within the albumin molecule removes positive charges from the molecule which creates a compound with a net negative charge that may serve as a ligand for scavenger receptors [123, 124].

Targeting to Kupffer cell is directed through mannose receptor using sugar moieties (like mannose and fucose) 
which are coupled to delivery system while targeting to sinusoidal endothelial cell is possible using hyaluron receptor as the target receptor $[5,6]$. Yamashita et al. investigated that when liposomes surface was modified by cetylmannoside (Man) then it could be useful for targeting to Kupffer cells [125]. Melgert et al. investigated that when dexamethasone was coupled to mannosylated albumin, it is selectively delivered to the Kupffer cell [126].

6.1.3. Hepatic Stellate Cells (HSC). Hepatic stellate cells (HSC) play a crucial role in the development of liver fibrosis because of their prominent role in extracellular matrix production, regulation of vascular tone, and production of inflammatory mediators such as transforming growth factor-b (TGF-b) and platelet-derived growth factor (PDGF). During fibrosis, in particular, these three processes are dearranged. At a certain point in the whole process, the HSC perpetuate the fibrogenesis by creating several autocrine loops, thus maintaining the process even without contribution of the other cell types. Therefore, these cells are major target for antifibrotic drugs [127-131]. The first target receptor chosen was the mannose-6-phosphate (M6P)/insulin-like growth factor II (M6P/IGFII) receptor, because it was reported to be highly unregulated on the cell membranes of activated HSC. HSA was modified with the sugar mannose-6-phosphate [132]. More importantly, the major part of the hepatic content was found in the HSC. Mannose-6-phosphate hepatic stellate cell (M6P-HSA) bound in particular to the activated HSC and a rapid internalization of the protein occurred via a receptormediated endocytotic route. Greupink et al. [133] showed that targeted delivery of coupled mycophenolic acid to the HSC-selective drug carrier mannose-6-phosphate modified human serum albumin results in a decrease in HSC activation, making it the first drug that is successfully delivered to this cell type. Adrian et al. [134] confirmed that M6P-HSAliposomes can be efficiently targeted to non-parenchymal cells, including HSC. In addition, two other HSC selective carriers were found. Instead of the derivatisation of albumin with specific sugars, albumin was now modified with cyclic peptide moieties (minimized proteins) that represented the binding domains of cytokines/growth factors responsible for binding to the activated HSC; for example, pentoxifylline is a promising drug that have been benefited from drug targeting strategies [7, 135-138].

Not only drugs but genetic materials are also of interest to be specifically targeted to HSC. Gene therapy is an elegant way to correct genetic deficiencies or to induce the production of essential proteins in a certain cell type. Adenoviral or lipid based nonviral vectors are alternatives to deliver genes and antisense material to cells [139-144]. A few reports on gene delivery to the cirrhotic liver or to HSC have appeared in the past few years, mostly using adenoviral mediated transduction methods. Yu et al. [145] reported a hepatic delivery of neuronal nitric oxide synthase (NOS) which resulted in a reduction of the intrahepatic resistance and portal pressure in in vivo models of liver fibrosis. Qi et al. [146] delivered a dominant-negative type II transforming growth factor-b receptor gene to the liver and found a blocking of transforming growth factor-b, which attenuated the development of liver fibrosis. Other examples of gene delivery in the context of liver fibrosis are the hepatic delivery of telomerase RNA by Rudolph et al. [147] and of urokinase-type plasminogen activator by Salgado et al. [148] and many more but without clinical usefulness.

6.1.4. Bile Duct Epithelial Cells. Bile duct epithelial cells play a key role in the pathogenesis of several hepatic diseases [149]. In primary biliary cirrhosis, these cells are the target of an autoimmune disease leading to the destruction of small intrahepatic bile ducts. The etiology is not yet clear, but the chronic inflammatory reaction around bile duct epithelial cells ultimately leads to irreversible cirrhosis and end-stage of liver failure.

Cell specific delivery to this cell type is still in its infancy. Until very recently, no drug carrier to this cell type was described. Oja et al. reported the expression of secretin receptors on cells of the biliary tract [150]. This receptor appears to be present on normal bile duct epithelial cells and ductules and they suggested that this receptor may be used for targeting to cholangiocarcinomas for therapy or diagnosis of this disease because of very high receptor expression on these carcinoma cells [151].

6.1.5. Hepatocellular Carcinoma Cells. Hepatocellular carcinoma (HCC) is one of the most common malignant tumors which can result from several liver diseases such as hepatitis $\mathrm{B}$ and $\mathrm{C}$ infections, metabolic liver diseases, and nonalcoholic fatty liver diseases [152]. Malignant transformation of hepatocytes induced by viral factors and several other mediators in the chronically inflamed area leads to hepatocarcinogenesis. HCC is the sixth most common cancer (in male) and the third leading cause of cancer associated deaths in the world $[153,154]$. In well-differentiated forms of HCC, hepatocytes express the asialoglycoprotein (ASPG) receptor [155]. Many drug delivery systems have already been developed to deliver drugs to this receptor using lactosaminated or galactosamine substituted drug carriers. In particular, polymers have been applied for the purpose of drug delivery to HCC [156-158] but modified albumins have also been explored $[159,160]$. The ASGP-receptor has also been employed as a target receptor for the delivery of genes with antineoplastic effects to the hepatocytes by making complexes of plasmids and polymers coupled to ASGP-receptor binding ligands [161]. Also other drug delivery systems such as cationic liposomes, virosomes, and adenoviral vectors have been exploited for the delivery of anticancer drugs and genes in HCC. Cheng et al. [162] synthesized GC/5-FU nanoparticles by combining galactosylated chitosan (GC) material with 5-FU, and tested its effect on liver cancer in vitro and in vivo. They conclude that sustained releases of GC/5-FU nanoparticles are more effective at targeting hepatic cancer cells than 5-FU monotherapy in the mouse orthotropic liver cancer mouse model. In the same year, Li et al. [163] concluded that the encapsulation of tetrandrine (Tet) and TX into nanoparticles retain the synergistic anticancer efficiency of Tet and TX against mice hepatoma H22 cells. Other researchers, Zhou et al. [164], synthesized N-lactosyl-dioleoylphosphatidylethanolamine (Lac-DOPE) and evaluated as a liver-specific targeting ligand via ASGP-R receptors for liposomal delivery of doxorubicin and reported 
that lactosylated liposomes are promising drug delivery vehicles for hepatocellular carcinoma. Recently, Zhang et al. [165] reported that mixed copolymer nanoparticles (NPs), self-assembled from $\beta$-cyclodextrin-grafted hyperbranched polyglycerol (HPG-g-CD) and lactobionic acid (LA)-grafted hyperbranched polyglycerol (HPG-g-LA), were utilized as carriers for hydrophobic antitumor drug, TX, resulting in enhanced hepatocellular-carcinoma uptake of these nanoparticles. Therefore, it was concluded that mixed copolymer NPs are efficient nanocarriers for hepatoma-targeted delivery of potent antitumor drugs.

\section{Expert Comments}

As per the report given by the WHO, approximately 1 in 12 persons worldwide or some 500 million people are living with chronic liver disease. It is forecasted that liver diseases may become a higher ranked cause of death in coming decades because of its complex pathogenesis which involves a variety of cells (parenchymal and non-parenchymal). The literature expressed that more than $90 \%$ of therapeutic drug is uptaken by normal tissues, whereas only $2 \%-5 \%$ is uptaken by diseased cells and moreover the current available therapy for liver diseases lacks adequate specificity and efficacy. To limit the severe side effects of conventional therapy, targeted delivery systems have shown an attractive prospect and opened a door for the treatment of chronic liver diseases. Hence, to increase the efficacy of drugs and decreasing their toxic side effects, encapsulation of drug in a carrier system is a common approach to achieve passive targeting. Nevertheless, passive targeting does not always lead to effective drug accumulation in a specific tissue or organ. Therefore, to increase the specificity of interaction between drug delivery system (DDS) and target cells or tissues as well as to increase the amount of drug delivery to the desired site of action, active targeting is needed. Such active targeting can be obtained by coupling a targeting moiety to the DDS, providing a selective and quantitative accumulation of the DDS at the target site. In this context, the concept of active liver targeting is undergoing clinical trial study, for example, doxorubicin coupled with magnet (MTC-DOX) is expected to target liver tumors directly. One of the recent approaches in which the drug is directly bound to a targeting moiety, for example, when norcantharidin directly bound to galactose group resulted in higher entrapment efficiency and low toxicity, still needs more focus to explore. Whatever the way selected for coupling targeting moiety to a DDS, the reaction has to be simple, fast, efficient, and reproducible. Both the drug loading efficiency and the drug release profile do not have to be significantly changed by targeting moieties coupling reactions. Furthermore, targeted DDS have to be nontoxic and stable enough to present a sufficiently long circulation half-life allowing them to reach and interact at their site of action.

It is also necessary to explore whether fabricated delivery system could also show the same targeting efficiency in humans with chronic liver diseases as in animal models. Efficient drug targeting to liver has certain limitations for medical applications: efficacy, safety, and cost as well as regulatory concerns.
Efficacy and safety of the developed formulations remain the prime goals with which these are developed. It is essential that the drug delivery vehicle should deliver the drug payload at its intended site of action at a required rate. An ideal carrier should be inert and devoid of any harmful effects. Another major restraint in designing the targeted delivery system is the high cost which makes productivity more difficult and the reduced ability to adjust the dosages. This could be overcome by encouraging the building of strong partnerships at the national and international level among academic and industrial partners with multidisciplinary expertise. Another hurdle is receiving the approval from drug regulatory authorities of respective countries such as Food and Drug Administration (FDA) in the USA, European Agency for the Evaluation of Medicinal products (EMEA) in Europe, and Pharmaceutical and Medical Device Agency, KIKO (PMDA, KIKO) in Japan due to long-term clinical trials owning to the lack of surrogate parameters to measure the effect of treatment. Duration of clinical trial can be reduced by coupling the radiolabel substance or fluorescent dye to DDS. This dual approach, that is, the use of the same carrier for imaging and treatment, will speed up the clinical trial study as well as approval from regulatory authorities.

Therefore, a lot of work remains to be done for the efficient targeting of drug to liver. Next improvements will certainly come from the introduction of new materials including stimuli-responsive polymers to elicit the challenge of targeting the drug to its specific site of action, to retain it for the desired duration, and to release it according to the correct time schedule.

\section{Conclusion}

The pathogenesis of liver diseases involves a variety of cells which makes the delivery of drug complicated. The most important aspects to improve the treatment via hepatoprotective drug are the design and synthesis of appropriate polymeric material to target specific cells of liver. Ingenious studies are required in coupling and selection of targeting moiety so that they could be translated from the bench research to the bedside. We have reviewed various aspects of selection of ligands and their coupling to drug/polymer which would potentially target parenchymal/non-parenchymal liver cells. The pharmacokinetic behaviour and physicochemical factors related with delivery systems have been considered to be primarily responsible for the improved targeting and therapeutic effectiveness; therefore, dealing with these factors during formulation development could lead to more promising treatments for acute and/or chronic liver diseases. These investigations require thorough inspection as well as innovative approaches to bring them into the global market at affordable price.

\section{Conflict of Interests}

The authors declare that they have no conflict of interests.

\section{Acknowledgments}

The authors are thankful to Council of Scientific and Industrial Research (CSIR), New Delhi, India, for providing 
financial assistance to Nidhi Mishra as CSIR-SRF (Grant no. 111102/2K1011) and CSIR-Central Institute of Medicinal and Aromatic Plants (CSIR-CIMAP), Lucknow, India, for providing necessary facilities under the project OLP-08.

\section{References}

[1] T. Abe, T. Masuda, and R. Satodate, "Phagocytic activity of Kupffer cells in splenectomized rats," Virchows Archiv A, vol. 413, no. 5, pp. 457-462, 1988.

[2] E. Wisse, F. Jacobs, B. Topal, P. Frederik, and B. De Geest, "The size of endothelial fenestrae in human liver sinusoids: implications for hepatocyte-directed gene transfer," Gene Therapy, vol. 15, no. 17, pp. 1193-1199, 2008.

[3] J. A. Champion, A. Walker, and S. Mitragotri, "Role of particle size in phagocytosis of polymeric microspheres," Pharmaceutical Research, vol. 25, no. 8, pp. 1815-1821, 2008.

[4] W. Jiang, B. Y. S. Kim, J. T. Rutka, and W. C. W. Chan, "Nanoparticle-mediated cellular response is size-dependent," Nature Nanotechnology, vol. 3, no. 3, pp. 145-150, 2008.

[5] X. Banquy, F. Suarez, A. Argaw et al., "Effect of mechanical properties of hydrogel nanoparticles on macrophage cell uptake," Soft Matter, vol. 5, no. 20, pp. 3984-3991, 2009.

[6] J.-O. You and D. T. Auguste, "Nanocarrier cross-linking density and $\mathrm{pH}$ sensitivity regulate intracellular gene transfer," Nano Letters, vol. 9, no. 12, pp. 4467-4473, 2009.

[7] C. He, Y. Hu, L. Yin, C. Tang, and C. Yin, "Effects of particle size and surface charge on cellular uptake and biodistribution of polymeric nanoparticles," Biomaterials, vol. 31, no. 13, pp. 36573666, 2010.

[8] K. Funato, R. Yoda, and H. Kiwada, "Contribution of complement system on destabilization of liposomes composed of hydrogenated egg phosphatidylcholine in rat fresh plasma," Biochimica et Biophysica Acta, vol. 1103, no. 2, pp. 198-204, 1992.

[9] K. Nishikawa, H. Arai, and K. Inoue, "Scavenger receptormediated uptake and metabolism of lipid vesicles containing acidic phospholipids by mouse peritoneal macrophages," Journal of Biological Chemistry, vol. 265, no. 9, pp. 5226-5231, 1990.

[10] P. J. Morgan, S. E. Harding, and K. Petrak, "Interactions of a model block copolymer drug delivery system with two serum proteins and myoglobin," Biochemical Society Transactions, vol. 18, no. 5, pp. 1021-1022, 1990.

[11] P. Opanasopit, M. Nishikawa, and M. Hashida, "Factors affecting drug and gene delivery: effects of interaction with blood components," Critical Reviews in Therapeutic Drug Carrier Systems, vol. 19, no. 3, pp. 191-233, 2002.

[12] A. Boddy, L. Aarons, and K. Petrak, "Efficiency of drug targeting: steady-state considerations using a three-compartment model," Pharmaceutical research, vol. 6, no. 5, pp. 367-372, 1989.

[13] K. Petrak and P. Goddard, "Transport of macromolecules across the capillary walls," Advanced Drug Delivery Reviews, vol. 3, no. 2, pp. 191-214, 1989.

[14] K.-I. Ogawara, M. Yoshida, K. Higaki et al., "Hepatic uptake of polystyrene microspheres in rats: effect of particle size on intrahepatic distribution," Journal of Controlled Release, vol. 59, no. 1, pp. 15-22, 1999.

[15] T. M. Allen, C. Hansen, F. Martin, C. Redemann, and A. F. YauYoung, "Liposomes containing synthetic lipid derivatives of poly(ethylene glycol) show prolonged circulation half-lives in vivo," Biochimica et Biophysica Acta, vol. 1066, no. 1, pp. 29-36, 1991.
[16] J. Wu, M. H. Nantz, and M. A. Zern, “Targeting hepatocytes for drug and gene delivery: emerging novel approaches and applications," Front Biosci, vol. 7, pp. d717-d725, 2002.

[17] P. C. N. Rensen, L. A. J. M. Sliedregt, M. Ferns et al., "Determination of the upper size limit for uptake and processing of ligands by the asialoglycoprotein receptor on hepatocytes in vitro and in vivo," Journal of Biological Chemistry, vol. 276, no. 40, pp. 3757737584, 2001.

[18] P. C. N. Rensen, M. C. M. Van Dijk, E. C. Havenaar, M. K. Bijsterbosch, J. K. Kruijt, and T. J. C. Van Berkel, "Selective liver targeting of antivirals by recombinant chylomicrons-a new therapeutic approach to hepatitis B," Nature Medicine, vol. 1, no. 3, pp. 221-225, 1995.

[19] C. Wolfrum, S. Shi, K. N. Jayaprakash et al., "Mechanisms and optimization of in vivo delivery of lipophilic siRNAs," Nature Biotechnology, vol. 25, no. 10, pp. 1149-1157, 2007.

[20] A. Akinc, W. Querbes, S. De et al., "Targeted delivery of RNAi therapeutics with endogenous and exogenous ligand-based mechanisms," Molecular Therapy, vol. 18, no. 7, pp. 1357-1364, 2010.

[21] M. K. Bijsterbosch, E. T. Rump, R. L. A. De Vrueh et al., "Modulation of plasma protein binding and in vivo liver cell uptake of phosphorothioate oligodeoxynucleotides by cholesterol conjugation," Nucleic Acids Research, vol. 28, no. 14, pp. 2717-2725, 2000.

[22] K. M. Wasan, D. R. Brocks, S. D. Lee, K. Sachs-Barrable, and S. J. Thornton, "Impact of lipoproteins on the biological activity and disposition of hydrophobic drugs: implications for drug discovery," Nature Reviews Drug Discovery, vol. 7, no. 1, pp. 8499, 2008

[23] S. Kunjachan, S. Jose, C. A. Thomas, E. Joseph, F. Kiessling, and T. Lammers, "Physicochemical and biological aspects of macrophage-mediated drug targeting in anti-microbial therapy," Fundamental and Clinical Pharmacology, vol. 26, no. 1, pp. 63-71, 2012.

[24] Y. Sato, K. Murase, J. Kato et al., "Resolution of liver cirrhosis using vitamin A-coupled liposomes to deliver siRNA against a collagen-specific chaperone," Nature Biotechnology, vol. 26, no. 4, pp. 431-442, 2008.

[25] H. Harashima, K. Sakata, K. Funato, and H. Kiwada, "Enhanced hepatic uptake of liposomes through complement activation depending on the size of liposomes," Pharmaceutical Research, vol. 11, no. 3, pp. 402-406, 1994.

[26] H.-F. Liang, C.-T. Chen, S.-C. Chen et al., "Paclitaxel-loaded poly $(\gamma$-glutamic acid)-poly(lactide) nanoparticles as a targeted drug delivery system for the treatment of liver cancer," Biomaterials, vol. 27, no. 9, pp. 2051-2059, 2006.

[27] P. N. Gupta, S. Mahor, A. Rawat, K. Khatri, A. Goyal, and S. P. Vyas, "Lectin anchored stabilized biodegradable nanoparticles for oral immunization. 1. Development and in vitro evaluation," International Journal of Pharmaceutics, vol. 318, no. 1-2, pp. 163173, 2006.

[28] D. C. Bibby, J. E. Talmadge, M. K. Dalal et al., "Pharmacokinetics and biodistribution of RGD-targeted doxorubicin-loaded nanoparticles in tumor-bearing mice," International Journal of Pharmaceutics, vol. 293, no. 1-2, pp. 281-290, 2005.

[29] B. Stella, S. Arpicco, M. T. Peracchia et al., "Design of folic acid-conjugated nanoparticles for drug targeting," Journal of Pharmaceutical Sciences, vol. 89, no. 11, pp. 1452-1464, 2000.

[30] D. L. Iden and T. M. Allen, "In vitro and in vivo comparison of immunoliposomes made by conventional coupling techniques 
with those made by a new post-insertion approach," Biochimica et Biophysica Acta, vol. 1513, no. 2, pp. 207-216, 2001.

[31] D. L. Iden and T. M. Allen, "In vitro and in vivo comparison of immunoliposomes made by conventional coupling techniques with those made by a new post-insertion approach," Biochimica et Biophysica Acta, vol. 1513, no. 2, pp. 207-216, 2001.

[32] B. Schechter, R. Arnon, Y. E. Freedman, L. Chen, and M. Wilchek, "Liver accumulation of TNP-modified streptavidin and avidin: potential use for targeted radio- and chemotherapy," Journal of Drug Targeting, vol. 4, no. 3, pp. 171-179, 1996.

[33] T. Ouchi, E. Yamabe, K. Hara, M. Hirai, and Y. Ohya, "Design of attachment type of drug delivery system by complex formation of avidin with biotinyl drug model and biotinyl saccharide," Journal of Controlled Release, vol. 94, no. 2-3, pp. 281-291, 2004.

[34] M. Mamede, T. Saga, T. Ishimori et al., "Hepatocyte targeting of 111In-labeled oligo-DNA with avidin or avidin-dendrimer complex," Journal of Controlled Release, vol. 95, no. 1, pp. 133141, 2004.

[35] X. Zeng, Y.-X. Sun, X.-Z. Zhang, and R.-X. Zhuo, "Biotinylated disulfide containing PEI/avidin bioconjugate shows specific enhanced transfection efficiency in HepG2 cells," Organic and Biomolecular Chemistry, vol. 7, no. 20, pp. 4201-4210, 2009.

[36] T. Marysael, M. Bauwens, Y. Ni, G. Bormans, J. Rozenski, and P. de Witte, "Pretargeting of necrotic tumors with biotinylated hypericin using ${ }^{123}$ I-labeled avidin: evaluation of a two-step strategy," Investigational New Drugs, vol. 30, no. 6, pp. 21322140, 2012.

[37] S.-N. Wang, Y.-H. Deng, H. Xu, H.-B. Wu, Y.-K. Qiu, and D.-W. Chen, "Synthesis of a novel galactosylated lipid and its application to the hepatocyte-selective targeting of liposomal doxorubicin," European Journal of Pharmaceutics and Biopharmaceutics, vol. 62, no. 1, pp. 32-38, 2006.

[38] Y.-I. Jeong, S.-J. Seo, I.-K. Park et al., "Cellular recognition of paclitaxel-loaded polymeric nanoparticles composed of $\operatorname{poly}(\gamma$ benzyl L-glutamate) and poly(ethylene glycol) diblock copolymer endcapped with galactose moiety," International Journal of Pharmaceutics, vol. 296, no. 1-2, pp. 151-161, 2005.

[39] Y. Hattori, S. Kawakami, S. Suzuki, F. Yamashita, and M. Hashida, "Enhancement of immune responses by DNA vaccination through targeted gene delivery using mannosylated cationic liposome formulations following intravenous administration in mice," Biochemical and Biophysical Research Communications, vol. 317, no. 4, pp. 992-999, 2004.

[40] P. Opanasopit, M. Sakai, M. Nishikawa, S. Kawakami, F. Yamashita, and M. Hashida, "Inhibition of liver metastasis by targeting of immunomodulators using mannosylated liposome carriers," Journal of Controlled Release, vol. 80, no. 1-3, pp. 283294, 2002.

[41] Q. Tian, W. Wang, X. He et al., "Glycyrrhetinic acid-modified nanoparticles for drug delivery: preparation and characterization," Chinese Science Bulletin, vol. 54, no. 18, pp. 3121-3126, 2009.

[42] Q. Tian, C.-N. Zhang, X.-H. Wang et al., "Glycyrrhetinic acidmodified chitosan/poly(ethylene glycol) nanoparticles for livertargeted delivery," Biomaterials, vol. 31, no. 17, pp. 4748-4756, 2010.

[43] G. Ashwell and J. Harford, "Carbohydrate-specific receptors of the liver," Annual Review of Biochemistry, vol. 51, pp. 531-554, 1982.

[44] J. U. Baenziges and D. Fiete, "Galactose and N-acetylgalactosamine-specific endocytosis of glycopeptides by isolated rat hepatocytes," Cell, vol. 22, no. 2, part 2, pp. 611-620, 1980.
[45] A. Kobayashi, M. Goto, K. Kobayashi, and T. Akaike, "Receptormediated regulation of differentiation and proliferation of hepatocytes by synthetic polymer model of asialoglycoprotein," Journal of Biomaterials Science. Polymer Edition, vol. 6, no. 4, pp. 325-342, 1994.

[46] H. Ise, N. Sugihara, N. Negishi, T. Nikaido, and T. Akaike, "Low asialoglycoprotein receptor expression as markers for highly proliferative potential hepatocytes," Biochemical and Biophysical Research Communications, vol. 285, no. 2, pp. 172-182, 2001.

[47] C. S. Cho, M. Goto, A. Kobayashi, K. Kobayashi, and T. Akaike, "Effect of ligand orientation on hepatocyte attachment onto the poly $(\mathrm{N}$-p-vinylbenzyl-o- $\beta$-D-galactopyranosyl-D-gluconamide) as a model ligand of asialoglycoprotein," Journal of Biomaterials Science, Polymer Edition, vol. 7, no. 12, pp. 1097-1104, 1996.

[48] Y. Iwamaru, Y. Shimizu, M. Imamura et al., "Lactoferrin induces cell surface retention of prion protein and inhibits prion accumulation," Journal of Neurochemistry, vol. 107, no. 3, pp. 636646, 2008.

[49] Y. A. Suzuki, V. Lopez, and B. Lönnerdal, "Mammalian lactoferrin receptors: structure and function," Cellular and Molecular Life Sciences, vol. 62, no. 22, pp. 2560-2575, 2005.

[50] P. P. Ward, S. Uribe-Luna, and O. M. Conneely, "Lactoferrin and host defense," Biochemistry and Cell Biology, vol. 80, no. 1, pp. 95-102, 2002.

[51] R. Huang, W. Ke, Y. Liu, C. Jiang, and Y. Pei, "The use of lactoferrin as a ligand for targeting the polyamidoamine-based gene delivery system to the brain," Biomaterials, vol. 29, no. 2, pp. 238-246, 2008.

[52] H. Chen, L. Tang, Y. Qin et al., "Lactoferrin-modified procationic liposomes as a novel drug carrier for brain delivery," European Journal of Pharmaceutical Sciences, vol. 40, no. 2, pp. 94102, 2010.

[53] M. Wei, Y. Xu, Q. Zou et al., "Hepatocellular carcinoma targeting effect of PEGylated liposomes modified with lactoferrin," European Journal of Pharmaceutical Sciences, vol. 46, no. 3, pp. 131-141, 2012.

[54] M. Gorria, X. Tekpli, M. Rissel et al., "A new lactoferrin- and iron-dependent lysosomal death pathway is induced by benzo[a]pyrene in hepatic epithelial cells," Toxicology and Applied Pharmacology, vol. 228, no. 2, pp. 212-224, 2008.

[55] D. J. Bennatt and D. D. McAbee, "Identification and isolation of a $45-\mathrm{kKa}$ calcium-dependent lactoferrin receptor from rat hepatocytes," Biochemistry, vol. 36, no. 27, pp. 8359-8366, 1997.

[56] D. J. Bennatt, Y. Y. Ling, and D. D. McAbee, "Isolated rat hepatocytes bind lactoferrins by the RHL-1 subunit of the asialoglycoprotein receptor in a galactose-independent manner," Biochemistry, vol. 36, no. 27, pp. 8367-8376, 1997.

[57] D. D. McAbee, X. Jiang, and K. B. Walsh, "Lactoferrin binding to the rat asialoglycoprotein receptor requires the receptor's lectin properties," Biochemical Journal, vol. 348, no. 1, pp. 113-117, 2000.

[58] D. D. McAbee, D. J. Bennatt, and Y. Y. L. Yuan Yuan Ling, "Identification and analysis of a CA2+-dependent lactoferrin receptor in rat liver: lactoferrin binds to the asialoglycoprotein receptor in a galactose-independent manner," Advances in Experimental Medicine and Biology, vol. 443, pp. 113-121, 1998.

[59] A. Pathak, S. P. Vyas, and K. C. Gupta, "Nano-vectors for efficient liver specific gene transfer," International Journal of Nanomedicine, vol. 3, no. 1, pp. 31-49, 2008.

[60] K. M. Kamruzzaman Selim, Y.-S. Ha, S.-J. Kim et al., "Surface modification of magnetite nanoparticles using lactobionic acid 
and their interaction with hepatocytes," Biomaterials, vol. 28, no. 4, pp. 710-716, 2007.

[61] K. M. Kamruzzaman Selim, Z.-C. Xing, H. Guo, and I.-K. Kang, "Immobilization of lactobionic acid on the surface of cadmium sulfide nanoparticles and their interaction with hepatocytes," Journal of Materials Science, vol. 20, no. 9, pp. 1945-1953, 2009.

[62] S. Díez, G. Navarro, and C. T. de ILarduya, "In vivo targeted gene delivery by cationic nanoparticles for treatment of hepatocellular carcinoma," Journal of Gene Medicine, vol. 11, no. 1, pp. 38-45, 2009.

[63] Y. Maitani, K. Kawano, K. Yamada, T. Nagai, and K. Takayama, "Efficiency of liposomes surface-modified with soybeanderived sterylglucoside as a liver targeting carrier in HepG2 cells," Journal of Controlled Release, vol. 75, no. 3, pp. 381-389, 2001.

[64] X.-R. Qi, W.-W. Yan, and J. Shi, "Hepatocytes targeting of cationic liposomes modified with soybean sterylglucoside and polyethylene glycol," World Journal of Gastroenterology, vol. 11, no. 32, pp. 4947-4952, 2005.

[65] J. Shi, X.-R. Qi, L. Yang, R. Fei, and L. Wei, "Liver targeting of cationic liposomes modified with soybean-derived sterylglucoside in vitro," Yaoxue Xuebao, vol. 41, no. 1, pp. 19-23, 2006.

[66] M. Negishi, A. Irie, N. Nagata, and A. Ichikawa, "Specific binding of glycyrrhetinic acid to the rat liver membrane," Biochimica et Biophysica Acta, vol. 1066, no. 1, pp. 77-82, 1991.

[67] T. Clerc, V. Sbarra, D. Botta-Fridlund et al., "Bile salt secretion by hepatocytes incubated with bile salts and liposomes or low density lipoproteins," Life Sciences, vol. 56, no. 4, pp. 277-286, 1995.

[68] G. Pütz, W. Schmider, R. Nitschke, G. Kurz, and H. E. Blum, "Synthesis of phospholipid-conjugated bile salts and interaction of bile salt-coated liposomes with cultured hepatocytes," Journal of Lipid Research, vol. 46, no. 11, pp. 2325-2338, 2005.

[69] G. G. Sahagian, J. Distler, and G. W. Jourdian, "Characterization of a membrane-associated receptor from bovine liver that binds phosphomannosyl residues of bovine testicular beta-galactosidase," Proceedings of the National Academy of Sciences of the United States of America, vol. 78, no. 7, pp. 4289-4293, 1981.

[70] A. Jayasree, S. Sasidharan, M. Koyakutty, S. Nair, and D. Menon, "Mannosylated chitosan-zinc sulphide nanocrystals as fluorescent bioprobes for targeted cancer imaging," Carbohydrate Polymers, vol. 85, no. 1, pp. 37-43, 2011.

[71] J. Rieger, H. Freichels, A. Imberty et al., "Polyester nanoparticles presenting mannose residues: toward the development of new vaccine delivery systems combining biodegradability and targeting properties," Biomacromolecules, vol. 10, no. 3, pp. 651-657, 2009.

[72] S. Kawakami, A. Sato, M. Nishikawa, F. Yamashita, and M. Hashida, "Mannose receptor-mediated gene transfer into macrophages using novel mannosylated cationic liposomes," Gene Therapy, vol. 7, no. 4, pp. 292-299, 2000.

[73] P. Muriel, M. G. Moreno, M. D. C. Hernández, E. Chávez, and L. K. Alcantar, "Resolution of liver fibrosis in chronic CCl4 administration in the rat after discontinuation of treatment: effect of silymarin, silibinin, colchicine and trimethylcolchicinic acid," Basic and Clinical Pharmacology and Toxicology, vol. 96, no. 5, pp. 375-380, 2005.

[74] J. Suojanen, S.-T. Vilen, P. Nyberg et al., "Selective gelatinase inhibitor peptide is effective in targeting tongue carcinoma cell tumors in vivo," Anticancer Research, vol. 31, no. 11, pp. 36593664, 2011.
[75] Z. Shen, W. Wei, H. Tanaka et al., "A galactosamine-mediated drug delivery carrier for targeted liver cancer therapy," Pharmacological Research, vol. 64, no. 4, pp. 410-419, 2011.

[76] L. Beljaars, K. Poelstra, G. Molema, and D. K. F. Meijer, “Targeting of sugar- and charge-modified albumins to fibrotic rat livers: the accessibility of hepatic cells after chronic bile duct ligation," Journal of Hepatology, vol. 29, no. 4, pp. 579-588, 1998.

[77] E. A. L. Biessen, D. M. Beuting, H. Vietsch, M. K. Bijsterbosch, and T. J. C. Van Berkel, "Specific targeting of the antiviral drug 5-Iodo 2'-deoxyuridine to the parenchymal liver cell using lactosylated poly-L-lysine," Journal of Hepatology, vol. 21, no. 5, pp. 806-815, 1994.

[78] B. Schechter, L. Chen, R. Arnon, and M. Wilchek, "Organ selective delivery using a tissue-directed sreptavidin-biotin system: targeting 5-fluorouridine via TNP-streptavidin," Journal of Drug Targeting, vol. 6, no. 5, pp. 337-348, 1999.

[79] L. Yuan, J. Wang, and W.-C. Shen, "Reversible lipidization of somatostatin analogues for the liver targeting," European Journal of Pharmaceutics and Biopharmaceutics, vol. 70, no. 2, pp. 615-620, 2008.

[80] J.-H. Han, Y.-K. Oh, D.-S. Kim, and C.-K. Kim, "Enhanced hepatocyte uptake and liver targeting of methotrexate using galactosylated albumin as a carrier," International Journal of Pharmaceutics, vol. 188, no. 1, pp. 39-47, 1999.

[81] D.-Q. Wu, B. Lu, C. Chang et al., "Galactosylated fluorescent labeled micelles as a liver targeting drug carrier," Biomaterials, vol. 30, no. 7, pp. 1363-1371, 2009.

[82] J. Zhang, C. Li, Z.-Y. Xue et al., "Fabrication of lactobionic-loaded chitosan microcapsules as potential drug carriers targeting the liver," Acta Biomaterialia, vol. 7, no. 4, pp. 1665-1673, 2011.

[83] D. Bhadra, A. K. Yadav, S. Bhadra, and N. K. Jain, "Glycodendrimeric nanoparticulate carriers of primaquine phosphate for liver targeting," International Journal of Pharmaceutics, vol. 295, no. 1-2, pp. 221-233, 2005.

[84] C. M. Sandrine, “Targeting approaches," in Nanotherapeutics, pp. 67-89, Pan Stanford Publishing, 2008.

[85] R. Zhao, S. Liu, S. Mao, and Y. Wang, "Study on liver targeting effect of vinegar-baked Radix Bupleuri on resveratrol in mice," Journal of Ethnopharmacology, vol. 126, no. 3, pp. 415-420, 2009.

[86] L. Chen, B. Schechter, R. Arnon, and M. Wilchek, "Tissue selective affinity targeting using the avidin-biotin system," Drug Development Research, vol. 50, no. 3-4, pp. 258-271, 2000.

[87] G. Di Stefano, C. Busi, M. Derenzini, D. Trerè, and L. Fiume, "Conjugation of 5-fluoro-2'-deoxyuridine with lactosaminated poly-1-lysine to reduce extrahepatic toxicity in the treatment of hepatocarcinomas," Italian Journal of Gastroenterology and Hepatology, vol. 30, no. 2, pp. 173-177, 1998.

[88] V. P. Torchilin, "Drug targeting," European Journal of Pharmaceutical Sciences, vol. 11, no. 2, pp. S81-S91, 2000.

[89] M. K. Bijsterbosch, H. Van De Bilt, and T. J. C. Van Berkel, "Specific targeting of a lipophilic prodrug of iododeoxyuridine to parenchymal liver cells using lactosylated reconstituted high density lipoprotein particles," Biochemical Pharmacology, vol. 52, no. 1, pp. 113-121, 1996.

[90] A. M. Dierling and Z. Cui, “Targeting primaquine into liver using chylomicron emulsions for potential vivax malaria therapy," International Journal of Pharmaceutics, vol. 303, no. 1-2, pp. 143-152, 2005.

[91] L. F. Lai and H. X. Guo, "Preparation of new 5-fluorouracil-loaded zein nanoparticles for liver targeting," International Journal of Pharmaceutics, vol. 404, no. 1-2, pp. 317-323, 2011. 
[92] L. Beljaars, "Albumin modified with mannose 6-phosphate: a potential carrier for selective delivery of antifibrotic drugs to rat and human hepatic stellate cells," Hepatology, vol. 29, no. 5, pp. 1486-1493, 1999.

[93] B. Wang, W. Li, K. Guo, Y. Xiao, Y. Wang, and J. Fan, "MiR-181b Promotes hepatic stellate cells proliferation by targeting p27 and is elevated in the serum of cirrhosis patients," Biochemical and Biophysical Research Communications, vol. 421, no. 1, pp. 4-8, 2012.

[94] L. J. Elrick, V. Leel, M. G. Blaylock et al., "Generation of a monoclonal human single chain antibody fragment to hepatic stellate cells-a potential mechanism for targeting liver anti-fibrotic therapeutics," Journal of Hepatology, vol. 42, no. 6, pp. 888-896, 2005.

[95] W. Huang, W. Wang, P. Wang et al., "Glycyrrhetinic acid-modified poly(ethylene glycol)-b-poly( $\gamma$-benzyl l-glutamate) micelles for liver targeting therapy," Acta Biomaterialia, vol. 6, no. 10, pp. 3927-3935, 2010.

[96] X. Li, Q. Wu, Z. Chen, X. Gong, and X. Lin, "Preparation, characterization and controlled release of liver-targeting nanoparticles from the amphiphilic random copolymer," Polymer, vol. 49, no. 22, pp. 4769-4775, 2008.

[97] P. Ma, S. Liu, Y. Huang, X. Chen, L. Zhang, and X. Jing, "Lactose mediated liver-targeting effect observed by ex vivo imaging technology," Biomaterials, vol. 31, no. 9, pp. 2646-2654, 2010.

[98] T. Gonzalo, E. G. Talman, A. Van De Ven et al., "Selective targeting of pentoxifylline to hepatic stellate cells using a novel platinum-based linker technology," Journal of Controlled Release, vol. 111, no. 1-2, pp. 193-203, 2006.

[99] H.-L. Jiang, J.-T. Kwon, E.-M. Kim et al., "Galactosylated poly(ethylene glycol)-chitosan-graft-polyethylenimine as a gene carrier for hepatocyte-targeting," Journal of Controlled Release, vol. 131, no. 2, pp. 150-157, 2008.

[100] M. Hashida, M. Nishikawa, and Y. Takakura, "Hepatic targeting of drugs and proteins by chemical modification," Journal of Controlled Release, vol. 36, no. 1-2, pp. 99-107, 1995.

[101] Y. Xu, X. Jin, Q. Ping et al., "A novel lipoprotein-mimic nanocarrier composed of the modified protein and lipid for tumor cell targeting delivery," Journal of Controlled Release, vol. 146, no. 3, pp. 299-308, 2010.

[102] Y. Hu, Y. Shen, B. Ji et al., "Liver-specific gene therapy of hepatocellular carcinoma by targeting human telomerase reverse transcriptase with pegylated immuno-lipopolyplexes," European Journal of Pharmaceutics and Biopharmaceutics, vol. 78, no. 3, pp. 320-325, 2011.

[103] P. J. Swart, T. Hirano, M. E. Kuipers et al., "Targeting of superoxide dismutase to the liver results in anti- inflammatory effects in rats with fibrotic livers," Journal of Hepatology, vol. 31, no. 6, pp. 1034-1043, 1999.

[104] Y. Hattori, S. Kawakami, F. Yamashita, and M. Hashida, "Controlled biodistribution of galactosylated liposomes and incorporated probucol in hepatocyte-selective drug targeting," Journal of Controlled Release, vol. 69, no. 3, pp. 369-377, 2000.

[105] F. Danhier, B. Vroman, N. Lecouturier et al., "Targeting of tumor endothelium by RGD-grafted PLGA-nanoparticles loaded with Paclitaxel," Journal of Controlled Release, vol. 140, no. 2, pp. 166173, 2009.

[106] F. Li, J.-Y. Sun, J.-Y. Wang et al., "Effect of hepatocyte growth factor encapsulated in targeted liposomes on liver cirrhosis," Journal of Controlled Release, vol. 131, no. 1, pp. 77-82, 2008.

[107] G. Huang, J. Diakur, Z. Xu, and L. I. Wiebe, "Asialoglycoprotein receptor-targeted superparamagnetic iron oxide nanoparticles,"
International Journal of Pharmaceutics, vol. 360, no. 1-2, pp. 197203, 2008.

[108] J. H. Maeng, D.-H. Lee, K. H. Jung et al., "Multifunctional doxorubicin loaded superparamagnetic iron oxide nanoparticles for chemotherapy and magnetic resonance imaging in liver cancer," Biomaterials, vol. 31, no. 18, pp. 4995-5006, 2010.

[109] S. Becker, M. Spiess, and H.-D. Klenk, "The asialoglycoprotein receptor is a potential liver-specific receptor for Marburg virus," Journal of General Virology, vol. 76, no. 2, pp. 393-399, 1995.

[110] X.-Q. Zhang, X.-L. Wang, P.-C. Zhang et al., "Galactosylated ternary DNA/polyphosphoramidate nanoparticles mediate high gene transfection efficiency in hepatocytes," Journal of Controlled Release, vol. 102, no. 3, pp. 749-763, 2005.

[111] M. Singh and M. Ariatti, “Targeted gene delivery into HepG2 cells using complexes containing DNA, cationized asialoorosomucoid and activated cationic liposomes," Journal of Controlled Release, vol. 92, no. 3, pp. 383-394, 2003.

[112] T. Shinoda, A. Maeda, S. Kagatani et al., "Specific interaction between galactose branched-cyclodextrins and hepatocytes in vitro," International Journal of Pharmaceutics, vol. 167, no. 1-2, pp. 147-154, 1998.

[113] H. Harashima and H. Kiwada, "Liposomal targeting and drug delivery: kinetic consideration," Advanced Drug Delivery Reviews, vol. 19, no. 3, pp. 425-444, 1996.

[114] A. Lin, Y. Liu, Y. Huang et al., "Glycyrrhizin surface-modified chitosan nanoparticles for hepatocyte-targeted delivery," International Journal of Pharmaceutics, vol. 359, no. 1-2, pp. 247-253, 2008.

[115] Q. Tian, C.-N. Zhang, X.-H. Wang et al., "Glycyrrhetinic acidmodified chitosan/poly(ethylene glycol) nanoparticles for livertargeted delivery," Biomaterials, vol. 31, no. 17, pp. 4748-4756, 2010.

[116] S. E. Gratton, P. A. Ropp, P. D. Pohlhaus et al., "The effect of particle design on cellular internalization pathways," Proceedings of the National Academy of Sciences of USA, vol. 105, no. 33, pp. 11613-11618, 2008.

[117] G. Sharma, D. T. Valenta, Y. Altman et al., "Polymer particle shape independently influences binding and internalization by macrophages," Journal of Controlled Release, vol. 147, no. 3, pp. 408-412, 2010.

[118] Y. Geng, P. Dalhaimer, S. Cai et al., "Shape effects of filaments versus spherical particles in flow and drug delivery," Nature Nanotechnology, vol. 2, no. 4, pp. 249-255, 2007.

[119] S.-Y. Lin, W.-H. Hsu, J.-M. Lo, H.-C. Tsai, and G.-H. Hsiue, "Novel geometry type of nanocarriers mitigated the phagocytosis for drug delivery," Journal of Controlled Release, vol. 154, no. 1, pp. 84-92, 2011.

[120] A. Arnida, M. M. Janát-Amsbury, A. Ray, C. M. Peterson, and H. Ghandehari, "Geometry and surface characteristics of gold nanoparticles influence their biodistribution and uptake by macrophages," European Journal of Pharmaceutics and Biopharmaceutics, vol. 77, no. 3, pp. 417-423, 2011.

[121] P. Decuzzi, B. Godin, T. Tanaka et al., "Size and shape effects in the biodistribution of intravascularly injected particles," Journal of Controlled Release, vol. 141, no. 3, pp. 320-327, 2010.

[122] N. Doshi, B. Prabhakarpandian, A. Rea-Ramsey, K. Pant, S. Sundaram, and S. Mitragotri, "Flow and adhesion of drug carriers in blood vessels depend on their shape: a study using model synthetic microvascular networks," Journal of Controlled Release, vol. 146, no. 2, pp. 196-200, 2010. 
[123] Z. Liu, W. Cai, L. He et al., "In vivo biodistribution and highly efficient tumour targeting of carbon nanotubes in mice," Nature Nanotechnology, vol. 2, no. 1, pp. 47-52, 2007.

[124] K. A. Beningo and Y.-L. Wang, "Fc-receptor-mediated phagocytosis is regulated by mechanical properties of the target," Journal of Cell Science, vol. 115, no. 4, pp. 849-856, 2002.

[125] C. Yamashita, H. Matsuo, K. Akiyama, and H. Kiwada, "Enhancing effect of cetylmannoside on targeting of liposomes to Kupffer cells in rats," International Journal of Pharmaceutics, vol. 70, no. 3, pp. 225-233, 1991.

[126] B. N. Melgert, P. Olinga, J. M. S. Van Der Laan et al., “Targeting dexamethasone to Kupffer cells: effects on liver inflammation and fibrosis in rats," Hepatology, vol. 34, no. 4, pp. 719-728, 2001.

[127] T. J. Merkel, S. W. Jones, K. P. Herlihy et al., "Using mechanobiological mimicry of red blood cells to extend circulation times of hydrogel microparticles," Proceedings of the National Academy of Sciences of the United States of America, vol. 108, no. 2, pp. 586-591, 2011.

[128] H. Hillaireau and P. Couvreur, "Nanocarriers' entry into the cell: relevance to drug delivery," Cellular and Molecular Life Sciences, vol. 66, no. 17, pp. 2873-2896, 2009.

[129] D. Schuppan, M. Ruehl, R. Somasundaram, and E. G. Hahn, "Matrix as a modulator of hepatic fibrogenesis," Seminars in Liver Disease, vol. 21, no. 3, pp. 351-372, 2001.

[130] R. C. Benyon and M. J. P. Arthur, "Extracellular matrix degradation and the role of hepatic stellate cells," Seminars in Liver Disease, vol. 21, no. 3, pp. 373-384, 2001.

[131] D. C. Rockey, "Hepatic blood flow regulation by stellate cells in normal and injured liver," Seminars in Liver Disease, vol. 21, no. 3, pp. 337-349, 2001.

[132] M. Lück, B. R. Paulke, W. Schröder, T. Blunk, and R. H. Müller, "Analysis of plasma protein adsorption on polymeric nanoparticles with different surface characteristics," Journal of Biomedical Materials Research, vol. 39, no. 3, pp. 478-485, 1998.

[133] R. Greupink, H. I. Bakker, C. Reker-Smit et al., "Studies on the targeted delivery of the antifibrogenic compound mycophenolic acid to the hepatic stellate cell," Journal of Hepatology, vol. 43, no. 5, pp. 884-892, 2005.

[134] J. E. Adrian, J. A. A. M. Kamps, G. L. Scherphof et al., "A novel lipid-based drug carrier targeted to the non-parenchymal cells, including hepatic stellate cells, in the fibrotic livers of bile duct ligated rats," Biochimica et Biophysica Acta, vol. 1768, no. 6, pp. 1430-1439, 2007.

[135] A. Raz, C. Bucana, and W. E. Fogler, "Biochemical, morphological, and ultrastructural studies on the uptake of liposomes by murine macrophages," Cancer Research, vol. 41, no. 2, pp. 487494, 1981.

[136] A. Chonn, S. C. Semple, and P. R. Cullis, "Association of blood proteins with large unilamellar liposomes in vivo. Relation to circulation lifetimes," Journal of Biological Chemistry, vol. 267, no. 26, pp. 18759-18765, 1992.

[137] K. Xiao, Y. Li, J. Luo et al., "The effect of surface charge on in vivo biodistribution of PEG-oligocholic acid based micellar nanoparticles," Biomaterials, vol. 32, no. 13, pp. 3435-3446, 2011.

[138] A. Mori, A. L. Klibanov, V. P. Torchilin, and L. Huang, "Influence of the steric barrier activity of amphipathic poly(ethyleneglycol) and ganglioside GM1 on the circulation time of liposomes and on the target binding of immunoliposomes in vivo," FEBS Letters, vol. 284, no. 2, pp. 263-266, 1991.

[139] A. Gabizon and D. Papahadjopoulos, "Liposome formulations with prolonged circulation time in blood and enhanced uptake by tumors," Proceedings of the National Academy of Sciences of the United States of America, vol. 85, no. 18, pp. 6949-6953, 1988.

[140] D. Peer and R. Margalit, "Tumor-targeted hyaluronan nanoliposomes increase the antitumor activity of liposomal doxorubicin in syngeneic and human xenograft mouse tumor models," Neoplasia, vol. 6, no. 4, pp. 343-353, 2004.

[141] D. Liu, F. Liu, and Y. K. Song, "Monosialoganglioside GM1 shortens the blood circulation time of liposomes in rats," Pharmaceutical Research, vol. 12, no. 4, pp. 508-512, 1995.

[142] D. Liu, Y. K. Song, and F. Liu, "Antibody dependent, complement mediated liver uptake of liposomes containing GM1," Pharmaceutical Research, vol. 12, no. 11, pp. 1775-1780, 1995.

[143] D. Liu, Q. Hu, and Y. K. Song, "Liposome clearance from blood: different animal species have different mechanisms," Biochimica et Biophysica Acta, vol. 1240, no. 2, pp. 277-284, 1995.

[144] A. Rigotti, S. L. Acton, and M. Krieger, "The class B scavenger receptors SR-BI and CD36 are receptors for anionic phospholipids," Journal of Biological Chemistry, vol. 270, no. 27, pp. 16221-16224, 1995.

[145] Q. Yu, R. Shao, H. S. Qian, S. E. George, and D. C. Rockey, "Gene transfer of the neuronal NO synthase isoform to cirrhotic rat liver ameliorates portal hypertension," Journal of Clinical Investigation, vol. 105, no. 6, pp. 741-748, 2000.

[146] Z. Qi, N. Atsuchi, A. Ooshima, A. Takeshita, and H. Ueno, "Blockade of type $\beta$ transforming growth factor signaling prevents liver fibrosis and dysfunction in the rat," Proceedings of the National Academy of Sciences of the United States of America, vol. 96, no. 5, pp. 2345-2349, 1999.

[147] K. L. Rudolph, S. Chang, M. Millard, N. Schreiber-Agus, and R. A. DePinho, "Inhibition of experimental liver cirrhosis in mice by telomerase gene delivery," Science, vol. 287, no. 5456, pp. 1253-1258, 2000.

[148] S. Salgado, J. Garcia, J. Vera et al., "Liver cirrhosis is reverted by urokinase-type plasminogen activator gene therapy," Molecular Therapy, vol. 2, no. 6, pp. 545-551, 2000.

[149] V. Terpstra and T. J. C. Van Berkel, "Scavenger receptors on liver Kupffer cells mediate the in vivo uptake of oxidatively damaged red blood cells in mice," Blood, vol. 95, no. 6, pp. 2157-2163, 2000.

[150] C. D. Oja, S. C. Semple, A. Chonn, and P. R. Cullis, "Influence of dose on liposome clearance: critical role of blood proteins," Biochimica et Biophysica Acta, vol. 1281, no. 1, pp. 31-37, 1996.

[151] T. M. Allen and C. Hansen, "Pharmacokinetics of stealth versus conventional liposomes: effect of dose," Biochimica et Biophysica Acta, vol. 1068, no. 2, pp. 133-141, 1991.

[152] Z. Panagi, A. Beletsi, G. Evangelatos, E. Livaniou, D. S. Ithakissios, and K. Avgoustakis, "Effect of dose on the biodistribution and pharmacokinetics of PLGA and PLGA-mPEG nanoparticles," International Journal of Pharmaceutics, vol. 221, no. 1-2, pp. 143-152, 2001.

[153] D. D. Chow, H. E. Essien, M. M. Padki, and K. J. Hwang, “Targeting small unilamellar liposomes to hepatic parenchymal cells by dose effect," Journal of Pharmacology and Experimental Therapeutics, vol. 248, no. 2, pp. 506-513, 1989.

[154] E. W. M. Van Etten, M. T. Ten Kate, S. V. Snijders, and I. A. J. M. Bakker-Woudenberg, "Administration of liposomal agents and blood clearance capacity of the mononuclear phagocyte system," Antimicrobial Agents and Chemotherapy, vol. 42, no. 7, pp. 1677-1681, 1998.

[155] H. Harashima, K. Sakata, and H. Kiwada, "Distinction between the depletion of opsonins and the saturation of uptake in the 
dose-dependent hepatic uptake of liposomes," Pharmaceutical Research, vol. 10, no. 4, pp. 606-610, 1993.

[156] A. Gabizon, D. Tzemach, L. Mak, M. Bronstein, and A. T. Horowitz, "Dose dependency of pharmacokinetics and therapeutic efficacy of pegylated liposomal doxorubicin (DOXIL) in murine models," Journal of Drug Targeting, vol. 10, no. 7, pp. 539548, 2002.

[157] T. L. Andresen, S. S. Jensen, and K. Jørgensen, "Advanced strategies in liposomal cancer therapy: problems and prospects of active and tumor specific drug release," Progress in Lipid Research, vol. 44, no. 1, pp. 68-97, 2005.

[158] F. Chellat, Y. Merhi, A. Moreau, and L. Yahia, "Therapeutic potential of nanoparticulate systems for macrophage targeting," Biomaterials, vol. 26, no. 35, pp. 7260-7275, 2005.

[159] P. L. Williams and H. Gray, Gray's Anatomy: The Anatomical Basis of Medicine and Surgery, Churchill Livingstone, 1995.

[160] Body Atlas, Octopus Books, 2008.

[161] A. C. Guyton, Textbook of Medical Physiology, Saunders, 1981.

[162] M. Cheng, B. He, T. Wan et al., "5-Fluorouracil nanoparticles inhibit hepatocellular carcinoma via activation of the p53 pathway in the orthotopic transplant mouse model," PLoS One, vol. 7, no. 10, article e47115, 2012.

[163] X. Li, H. Xu, X. Dai, Z. Zhu, B. Liu, and X. Lu, "Enhanced in vitro and in vivo therapeutic efficacy of codrug-loaded nanoparticles against liver cancer," International Journal of Nanomedicine, vol. 7, pp. 5183-5190, 2012.

[164] X. Zhou, M. Zhang, B. Yung et al., "Lactosylated liposomes for targeted delivery of doxorubicin to hepatocellular carcinoma," International Journal of Nanomedicine, vol. 7, pp. 5465-5474, 2012.

[165] X. Zhang, X. Zhang, P. Yu et al., "Hydrotropic polymeric mixed micelles based on functional hyperbranched polyglycerol copolymers as hepatoma-targeting drug delivery system," Journal of Pharmaceutical Sciences, vol. 102, no. 1, pp. 145-1453, 2013. 

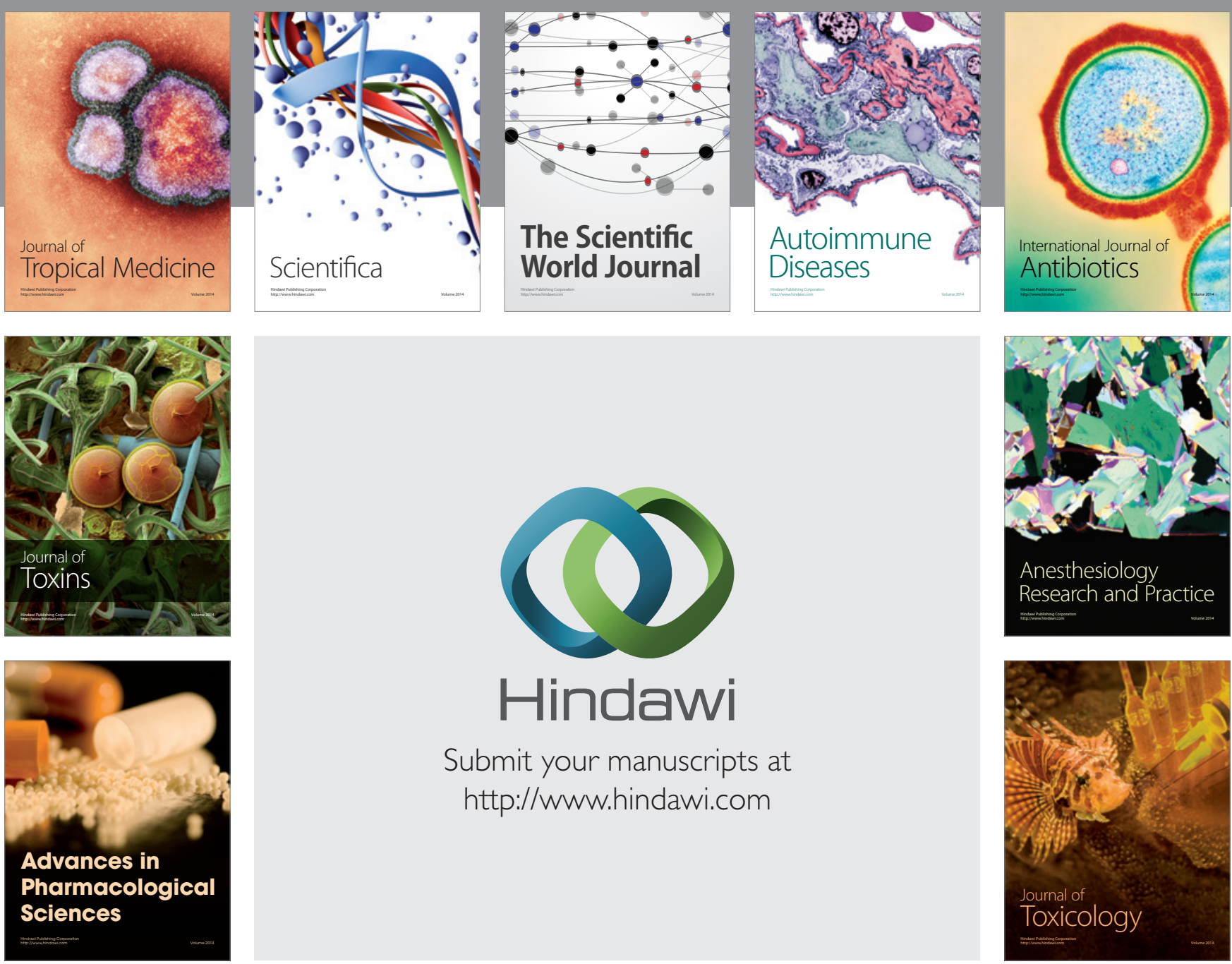

\section{Hindawi}

Submit your manuscripts at

http://www.hindawi.com
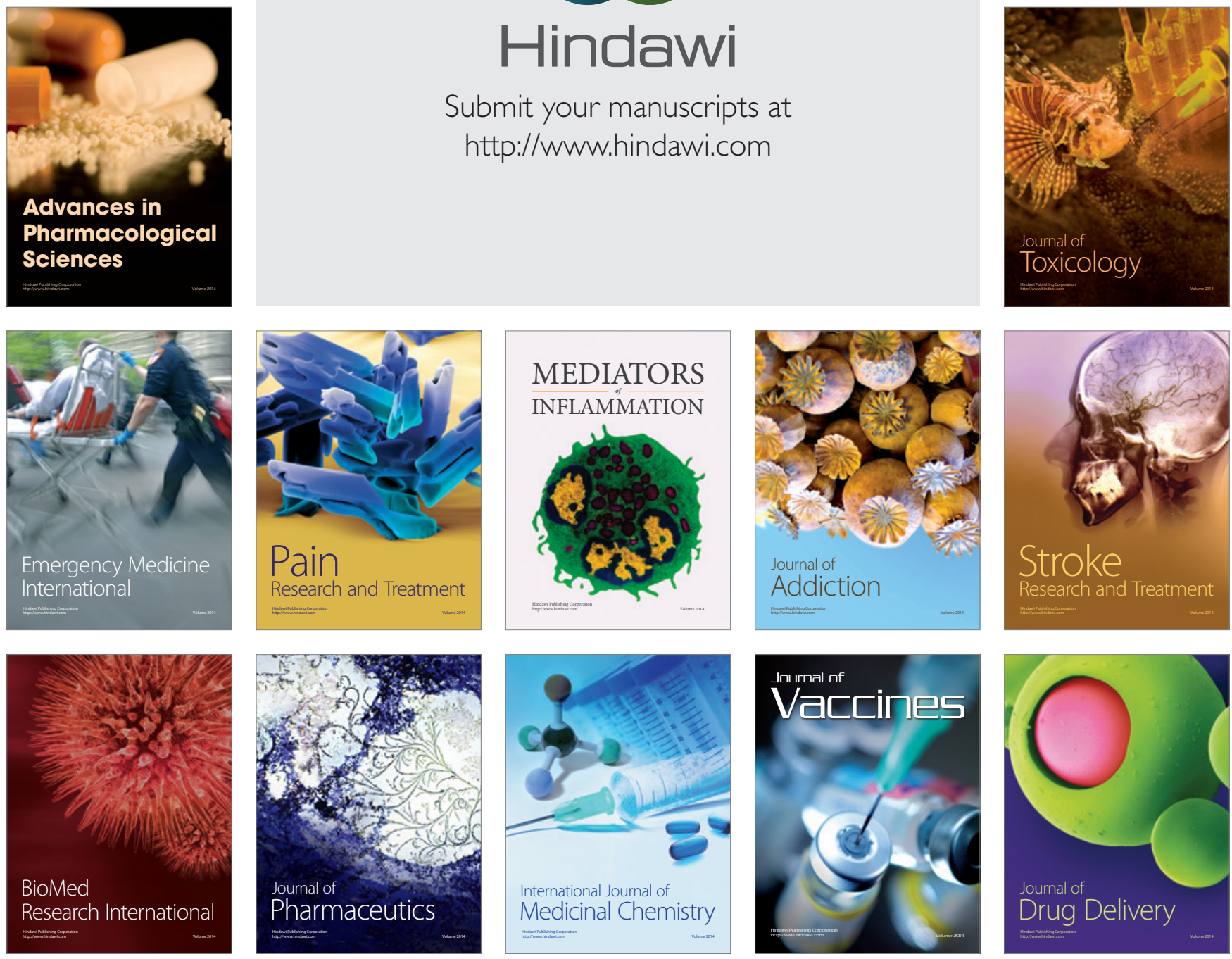